\title{
RAP1 and telomere structure regulate telomere position effects in Saccharomyces cerevisiae
}

\author{
Gabriele Kyrion, ${ }^{1,3}$ Ke Liu, ${ }^{1-3}$ Cheng Liu, ${ }^{1,2}$ and Arthur J. Lustig, ${ }^{1,2}$ \\ ${ }^{1}$ Molecular Biology Program, Sloan-Kettering Institute, Memorial Sloan-Kettering Cancer Center, and ${ }^{2}$ Graduate Program \\ in Molecular Biology, Cornell University Graduate School of Medical Sciences, New York, New York 10021 USA
}

To investigate the role of the yeast telomere-, silencing-, and UAS-binding protein RAP1 in telomere position effects, we have characterized two sets of mutant cells: (1) a set of rap1 alleles (termed the rap1 ${ }^{t}$ alleles) that produce truncated RAP1 proteins missing the carboxy-terminal 144-165 amino acids; and (2) null mutants of the RIF1 gene, encoding a protein capable of interaction with the carboxyl terminus of RAP1. The data presented here indicate that loss of the carboxyl terminus of RAP1 abolishes position effects at yeast telomeres and diminishes silencing at the $H M L$ locus. Elimination of position effects in these cells is associated with increased accessibility to the Escherichia coli dam methylase in vivo. Thus, the carboxy-terminal domain of RAP1 is required for telomere position effects. In contrast, rif1 deletion alleles increase the frequency of repressed cells. Using the rap $1^{t}$ alleles to generate wild-type cells differing only in telomere tract lengths, we also show that telomere position effects are highly sensitive to changes in the size (or structure) of the telomeric tract. Longer poly $\left(\mathrm{G}_{1-3} T\right)$ tracts can increase the frequency of transcriptional repression at the telomere, suggesting that telomeric $\operatorname{poly}\left(\mathrm{G}_{1-3} T\right)$ tracts play an active role in the formation or stability of subtelomeric transcriptional states.

[Key Words: RAP1; telomere position effects; dam methylase; HML silencing; RIF1]

Received January 15, 1993; revised version accepted May 11, 1993.

Telomeres, the unique protein-DNA structures present at the termini of linear eukaryotic chromosomes, confer metastable position effects on the transcription of neighboring genes (Levis et al. 1985; Gottschling et al. 1990). In the yeast Saccharomyces cerevisiae, genes positioned adjacent to the ends of chromosomes undergo repetitive cycles of activation and repression, with each state maintained for multiple generations (Gottschling et al. 1990). Interestingly, genes subject to these telomere position effects are only weakly accessible to methylation in vivo by exogenously introduced Escherichia coli dam methylase, leading to the suggestion that changes in chromatin structure may be associated with these repressive effects (Gottschling 1992). Although telomere position effects appear to require a physical terminus (Gottschling et al. 1990), the involvement of telomeric poly $\left(\mathrm{G}_{1-3} \mathrm{~T}\right)$ tracts in this process has remained unknown.

Telomere position effects share trans-acting requirements with the silencing of the cryptic mating-type information present at $H M L \alpha$ and $H M R$ a located 12 and 30 $\mathrm{kb}$ from the left and right telomeres of chromosome III, respectively (Aparicio et al. 1991; Laurenson and Rine 1992). The repressed state at $H M L \alpha$ and $H M R \mathbf{a}$ is depen-

${ }^{3}$ These authors contributed equally to this study. dent on the SIR1, SIR2, SIR3, and SIR4 gene products. Mutations in any one of these four genes lead to derepression of mating-type information. In addition, mutations in the two genes encoding the subunits of the amino-terminal acetyltransferase (NAT1 and ARD1) and amino-terminal deletions of histone $\mathrm{H} 4$ result in partial or complete derepression of $H M L \alpha$ and $H M R \mathbf{a}$. With the exception of $\operatorname{sir} 1$, mutations in all of these gene products relieve the repression of telomere-adjacent genes (Aparicio et al. 1991) and, where tested, lead to a deprotection against dam methylation in vivo (Gottschling 1992). The common dependence of telomere position effects and HM silencing on these gene products suggests that these two processes may be mechanistically linked. Although telomeric position is not required for HM silencing, it may nonetheless influence this process, as the cis-acting requirements for the silencing of $H M L \alpha$ on a circular plasmid and at its normal subtelomeric chromosome position are substantially different (Mahoney and Broach 1989; Mahoney et al. 1991).

The UAS-, silencer-, and telomere-binding protein RAP1 has been implicated in the control of HM silencing. Binding sites for this protein are located in the silencer elements present at both $H M L \alpha$ and $H M R \mathbf{a}$ (Shore et al. 1987). At HMRa, sites for the binding of three activities ABF1, ORC [the activity thought to bind to the 
consensus autonomously replicating sequence (ARS) element], and RAP1 are present (Shore et al. 1987; Bell and Stillman 1992; for review, see Laurenson and Rine 1992). Although deletions of any one of these sites do not have a substantial effect on silencing, elimination of any two sites results in the total derepression of this locus (Brand et al. 1987). Direct evidence for a role of RAP1 in silencing at HMRa has been provided by the identification of carboxy-terminal missense mutations of rap1 (the rap $1^{s}$ alleles) that, in strains deleted for the consensus ARS element at $H M R(H M R \Delta A)$, cause a loss of $H M R$ silencing (Sussel and Shore 1991). Overproduction of the carboxyl terminus of RAP1 similarly results in a loss of silencing of the $H M R \Delta A$ silencer, suggesting that a protein interacting with the carboxyl terminus may be titrated in these strains (Hardy et al. 1992a). One such protein, RIF1, has recently been identified (Hardy et al. 1992b). Null mutations in RIF1 confer rap1 $1^{\text {s}}$-like phenotypes. The observations that the $\operatorname{Rap}^{\mathrm{s}}$ proteins are defective in their interaction with wild-type RIF1, and that a specific missense allele of rif1 can suppress this defect, argue for a direct physical association between the carboxyl terminus of RAPl and RIFl. At the HML $\alpha$ locus, two functionally redundant silencer elements, E and I, are present (Hofmann et al. 1989; Mahoney and Broach 1989; Mahoney et al. 1991; Laurenson and Rine 1992). The E element contains a RAP1-binding site which, when deleted, results in partial derepression of $H M L$ in strains lacking the I element (Mahoney et al. 1991). Although these data suggest that RAP1 is involved in $H M L$ silencing, rap1 mutations affecting $H M L$ silencing have not yet been identified (D. Shore, pers. comm.).

High-affinity RAP1-binding sites are also present within the poly $\left(\mathrm{G}_{1-3} \mathrm{~T}\right)$ tract of the yeast telomere (Buchman et al. 1988; Longtine et al. 1989). Recent studies have demonstrated that RAPl binds to the yeast telomere in vivo, where it plays a role in the maintenance of telomere size and stability (Conrad et al. 1990; Lustig et al. 1990; Klein et al. 1992; Kyrion et al. 1992). The role, if any, of RAP1 in telomere position effects has, however, remained unknown. While the rap $1^{s}$ alleles have substantial effects on $H M R$ silencing, these alleles do not influence telomere position effects (E. Wiley and V. Zakian, pers. comm.).

We have recently identified a set of alleles (termed the rap $1^{t}$ alleles) containing nonsense codons that result in a truncation of the carboxy-terminal 144-165 amino acids of the 827-amino-acid RAP1 protein (Kyrion et al. 1992). Whereas these truncated Rap $1^{t}$ proteins are capable of specific DNA binding, they have numerous effects on telomere length and stability in vivo. First, the rap $1^{t}$ mutants display promiscuous telomere elongation, with poly $\left(G_{1-3} T\right)$ tracts increasing in size from 300 bp present in wild type to $>4 \mathrm{~kb}$. Second, rap $1^{t}$ telomeres are highly unstable and are capable of undergoing rapid deletion of up to $3 \mathrm{~kb}$ of tract in a single generation. Third, both chromosome loss and nondisjunction are elevated in rap $1^{t}$ alleles.

Because the carboxyl terminus has been implicated in the silencing function of RAP1, we sought to test whether the terminally truncated rap $1^{t}$ alleles influence either telomere position effects or $H M L \alpha$ silencing. Our results demonstrate that a carboxy-terminal function of RAP1 is an absolute requirement for telomere position effects. We also demonstrate that the structure of the telomere tract itself can influence the efficiency of telomere position effects.

\section{Results}

Deletion of the carboxyl terminus of RAP1 results in loss of telomere position effects

To investigate the role of RAP1 in telomere position effects, we tested the ability of cells containing a mutation in one of the rap $1^{t}$ alleles, rap1-17, to repress the $U R A 3$ gene when introduced adjacent to the telomeric tract on either the right arm of chromosome $\mathrm{V}\left(\mathrm{V}_{\mathrm{R}}\right)$ or the left arm of chromosome VII $\left(\mathrm{VII}_{\mathrm{L}}\right)$. The rap1-17 gene encodes a protein that, while able to bind specifically to its cognate site, is missing the terminal 165 amino acids (Kyrion et al. 1992). The frequency of $u r a 3^{-}$cells was assayed by determining the fraction of cells capable of growth on medium containing 5-fluoro-orotic acid (5-FOA), a uracil analog that allows the growth of $u r a 3^{-}$, but not $U R A 3^{+}$, cells (Fig. 1; Table 1). In this genetic background, wildtype RAP1 cells containing URA3-marked $\mathrm{V}_{\mathrm{R}}$ and $\mathrm{VII}_{\mathrm{L}}$ telomeres give rise to FOA-resistant colonies at median frequencies of $1 \%$ and $52 \%$, respectively [Table $1 ; R A P 1$ (Chr)]. A similar context-dependent difference in the FOA $^{\mathrm{r}}$ frequencies of these telomeres has been described previously (Gottschling et al. 1990). In contrast, rap1-17 cells produce colonies on FOA medium only rarely $\left(<1 \times 10^{-7}\right)$ at both $\mathrm{V}_{\mathrm{R}}$ and $\mathrm{VII}_{\mathrm{L}}$ ends [Table 1; rap1-17 (Chr)]. This phenotype is not the consequence of a general defect in the ability of these strains to grow on FOAcontaining medium, because $100 \%$ of rap1-17 ura3-1 cells are FOA ${ }^{\mathbf{r}}$ (Fig.1; data not shown). Cells containing the rap1-18 allele, which encodes a protein missing the terminal 144 amino acids, also display a marked reduction in the frequency of FOA $^{\mathrm{r}}$ colonies, arising at a frequency of $8 \times 10^{-6}$. The magnitude of URA3 derepression observed in rap1-17 and rap1-18 cells is similar to that observed for mutations in the SIR2 gene (Fig. 1; Table 1; Aparicio et al. 1991). We have observed no differences from wild-type expression when URA3 is placed at internal positions in these strains (Fig. 1). Derepression of telomeric genes is recessive. Diploids heterozygous for rap1-17 display wild-type frequencies of FOA ${ }^{\mathrm{r}}$ colonies (Table 1, bottom).

Three lines of evidence indicate that the observed derepression of URA3 is the consequence of the rap1-17 mutation. First, loss of telomere position effects is tightly linked genetically to RAP1: Following crosses between rap $^{t}$ and wild-type cells, only rap $1^{t}$ spore colonies containing the marked telomere are fully sensitive to FOA (data not shown). Second, replacement of a wildtype copy of RAP1 with the rap1-17 gene by a plasmid shuffle (Kyrion et al. 1992) is sufficient to confer URA3 derepression (Table 1). While strains carrying the wild- 
Figure 1. rap1-17 and rap1-18 mutations derepress URA3 expression at the telomere. Serial 10-fold dilutions of wild-type, rap1-17, rap1-18, and sir2::TRP1 strains containing $U R A 3$-marked $\mathrm{V}_{\mathrm{R}}$ or $\mathrm{VII}_{\mathrm{L}}$ telomeres were plated onto uracil omission media (SC-ura), FOA-containing media (FOA), and synthetic complete media (SC) and grown at $30^{\circ} \mathrm{C}$. Also plated are an unmarked ura3-1 rap1-17 strain and a rap117 strain carrying URA3 at an internal position on chromosome VII. The rap1-17 and rap1-18 strains, although slower growing, have wild-type levels of viability on SC media. Strains used are as follows (top to bottom): KL4-5b, KL5-2c, KL4-5b $\Delta$ sir2, AJL364-1c, AJL278-4d, AJL275-2a-VII URA, AJL369-5b, AJL399-4b, and AJL387$5 \mathrm{a} \Delta \operatorname{sir} 2$.

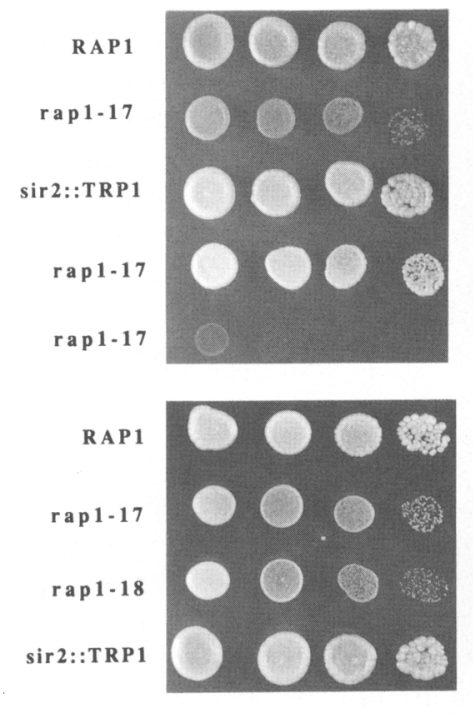

SC-ura
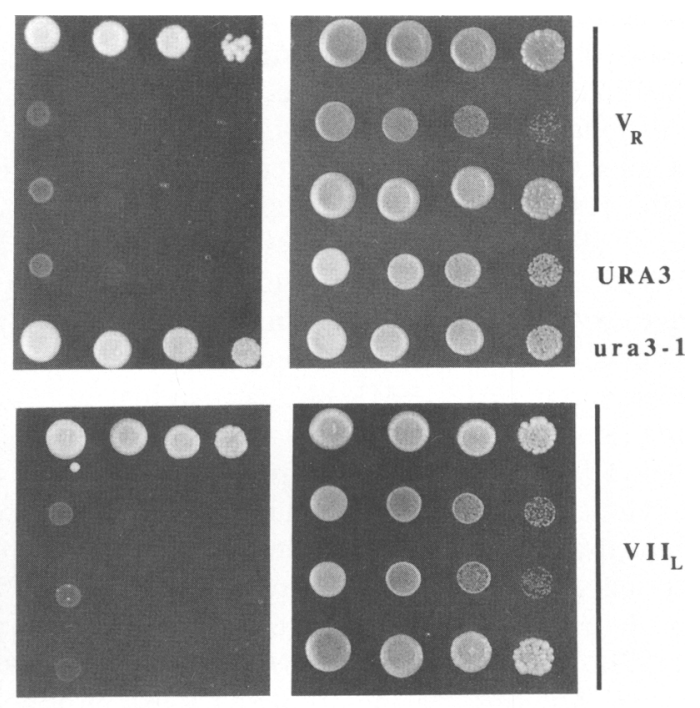

FOA

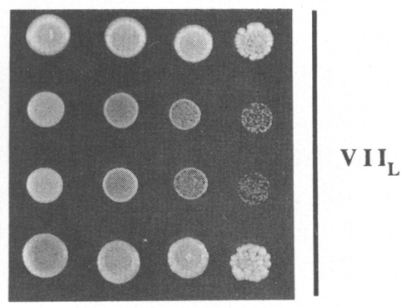

SC type copy of $R A P 1$ on a centromeric plasmid form colonies on FOA medium at a median frequency of $4 \times 10^{-4}$, replacement of the wild-type copy with the rap1-17 gene generates cells that are fully sensitive to FOA [Table 1, cf. RAP1 (plasmid) and rap1-17 (plasmid)]. Third, the presence of a wild-type RAP1 gene on a CEN plasmid fully complements the effects of an integrated copy of rap1-17 on gene expression at $\mathrm{VII}_{\mathrm{L}}$ (Table 1, rap1-17) RAP1).

To confirm that the FOA assay measures differences in URA3 expression, we compared the levels of URA3 transcripts produced in wild-type and rap1-17 strains carrying both a URA3-marked telomere at $\mathrm{VII}_{\mathrm{L}}$ and a deletion allele of URA3, ura3 31 , at its normal locus on chromosome V (Fig. 2). The level of URA3 mRNA in logarithmically growing cells was determined by Northern analysis. Cells wild-type for RAP1 contained telomeric URA3 mRNA at levels below detection (Fig. 2, lane 1). A similarly high level of telomeric repression has been described previously (Aparicio et al. 1991) and is the likely consequence of a reduction in the abundance of transcripts in the fraction of cells that express URA3. In contrast, rap1-17 cells produced these transcripts at levels close to those found in strains carrying only the ura3-1 allele (Fig. 2, lanes 2,3). We estimate a difference of $>10$-fold between the level of telomeric transcripts in wild-type and rap1-17 cells, similar to the derepression observed in other mutants defective in telomere position effects (Aparicio et al. 1991). In contrast, mRNA levels from the ura3-1 locus were identical in both wild-type and rap1-17 strains (Fig. 2, lanes 4,5).

To test whether the effect of rap $1^{t}$ alleles on telomere position effects is specific to the URA3-marked telomeres, we introduced the $A D E 2$ gene adjacent to the telomeric tract on chromosome $\mathrm{VII}_{\mathrm{L}}$ (Fig. 3 , top). The repressed and derepressed states were subsequently monitored visually through the production of red and white sectors, respectively (Gottschling et al. 1990). In this genetic background, $\sim 10 \%$ of cells wild-type for RAP1 and containing a telomeric $A D E 2$ gene produced white colonies with red sectors. A smaller fraction $(\sim 2 \%)$ formed red colonies with white sectors (Fig. 3, upper left; Fig. 6, below). In contrast, of $>5000$ rap $1-17$ colonies assayed, all but 1 produced a white colony color, and none of these were capable of forming red sectors (Fig. 3, upper right), indicating that these cells cannot repress $A D E 2$ expression at the telomere.

\section{Derepression of telomeric gene expression in rapl-17 cells is independent of poly $\left(G_{1-3} T\right)$ tract length}

Recent studies have indicated that the strength of position effects at the telomere is inversely proportional to the distance of the gene from the telomere, with the frequency of repressed states decreasing with increasing distance (Renauld et al., this issue). This effect may be the consequence of an increased distance either between the gene and the beginning of the telomere tract or between the gene and the physical end of the chromosome. One possible explanation of our data, therefore, is that the extended telomere tract in rap $1^{t}$ cells eliminates telomere position effects by increasing the distance between the marker gene and the chromosomal terminus.

To test this hypothesis, we examined URA3 expression in wild-type spore colonies inheriting elongated rap1-17 telomeres from heterozygous diploids (see Materials and methods). Wild-type strains inheriting $V_{R}$ telomeres of $\sim 1.4 \mathrm{~kb}$ nonetheless produced a high frequency of $\mathrm{FOA}^{\mathrm{r}}$ colonies, indicating that increased telomere length alone is insufficient to explain the loss of position effects [Table 1, cf. RAP1 (Chr)-300 bp with RAP1 (Chr)-1370 bp]. A similar result was obtained when a series of plasmid shuffles was used to generate a set of isogenic wild-type and rap1-17 strains differing 
Table 1. FOA $A^{r}$ frequencies in rap $1^{\mathrm{t}}$ cells carrying URA3-marked telomeres

\begin{tabular}{|c|c|c|c|}
\hline $\begin{array}{l}\text { URA3 } \\
\text { locus }\end{array}$ & $\begin{array}{l}\text { Genotype }^{a} \\
\text { (site) }\end{array}$ & $\begin{array}{l}\text { Tract } \\
\text { size }^{b} \\
(b p \mid\end{array}$ & $\begin{array}{l}\text { Fraction FOA } \\
\text { (range of values; }^{\mathrm{r}} \\
\text { number } \\
\text { of colonies) }\end{array}$ \\
\hline \multirow[t]{7}{*}{$\mathrm{V}_{\mathrm{R}}$} & RAP1 $(\mathrm{Chr})^{\mathrm{d}}$ & 300 & $\begin{array}{l}1.1 \times 10^{-2} \\
(0.03-6.5 ; 30)\end{array}$ \\
\hline & $R A P 1(\mathrm{Chr})^{\mathrm{d}, \mathrm{e}}$ & 1370 & $\begin{array}{l}3.2 \times 10^{-2} \\
(0.006-25 ; 24)\end{array}$ \\
\hline & RAP1 (plasmid) $)^{\mathrm{f}}$ & 350 & $\begin{array}{l}4.3 \times 10^{-4} \\
(0-63.0 ; 16)^{8}\end{array}$ \\
\hline & $R A P 1$ (plasmid) $^{f}$ & 1100 & $\begin{array}{l}5.8 \times 10^{-4} \\
(3.3-35 ; 8)\end{array}$ \\
\hline & rap1-17 (Chr) & $700-2000$ & $<1.0 \times 10^{-7}(16)$ \\
\hline & rap1-17 (plasmid) & 650 & $<1.6 \times 10^{-7}(8)$ \\
\hline & sir2::TRP1 (Chr) & 300 & $<1.0 \times 10^{-7}(20)$ \\
\hline \multirow[t]{6}{*}{$\begin{array}{l}\mathrm{VI}_{\mathrm{L}} \\
\text { haploids }\end{array}$} & $R A P 1$ (Chr) & & $\begin{array}{l}5.2 \times 10^{-1} \\
\quad(3.4-7.8 ; 15)\end{array}$ \\
\hline & rap1-17 (Chr) & & $<1.0 \times 10^{-7}(26)$ \\
\hline & rap1-17 / RAP1 & & $4.0 \times 10^{-1}$ \\
\hline & (Chr/plasmid) & & $(2.5-7.6 ; 10)$ \\
\hline & rap1-18 (Chr) & & $\begin{array}{l}8.4 \times 10^{-6} \\
\quad(0-151 ; 15)^{\mathrm{h}}\end{array}$ \\
\hline & sir2::TRP1 (Chr) & & $<1.5 \times 10^{-7}(10)$ \\
\hline \multirow[t]{3}{*}{$\begin{array}{l}\mathrm{VII}_{\mathrm{L}} \\
\text { diploids }\end{array}$} & $R A P 1 / R A P 1$ & & $\begin{array}{l}3.7 \times 10^{-1} \\
\quad(3.5-5.6 ; 5)\end{array}$ \\
\hline & RAP1/rap1-17 & & $\begin{array}{l}2.5 \times 10^{-1} \\
(2.3-4.8 ; 5)\end{array}$ \\
\hline & rap1-17/rap1-17 & & $<1.7 \times 10^{-7}(10)$ \\
\hline
\end{tabular}

a/Chr) Chromosomal rap1 allele; (plasmid) rap1 allele on a CEN plasmid in a strain containing a rap1::LEU2 disnuption at its chromosomal locus.

${ }^{b}$ Average poly $\left(G_{1-3} T\right)$ tract length is presented. In the case of rap1-17 strains, the average length varied in different strains and subculturings between 700 and $2000 \mathrm{bp}$.

${ }^{\mathrm{C}}$ Observed FOA $^{\mathrm{r}}$ frequencies are presented as median values, with the range of values and the number of colonies assayed in parentheses.

${ }^{\mathrm{d}} \mathrm{RAP} 1$ (Chr)-300 and RAP1 (Chr)-1370 represent isogenic wildtype strains differing only in tract size.

ePooled data from strains $383-3 \mathrm{c}$ s0, 384-1c, and 384-4a presented in Table 2.

${ }^{\mathrm{R}} \mathrm{RAP1}$ (plasmid)-350 and RAP1 (plasmid)-1100 represent isogenic wild-type strains derived from a plasmid shuffle and differ only in telomere tract size.

${ }^{8}$ Of the 16 colonies tested, 2 failed to yield any FOA ${ }^{\mathrm{r}}$ cells in the population tested $(0 / 8,800$ and $0 / 12,400)$.

${ }^{\mathrm{b}}$ Of the 15 colonies tested, 1 failed to yield any FOA ${ }^{x}$ cells in the population tested $\left(0 / 1.3 \times 10^{7}\right)$.

only in the length of the URA3-marked $\mathrm{V}_{\mathrm{R}}$ telomere. Following a plasmid shuffle, wild-type cells inheriting elongated telomeres from rap1-17 cells displayed FOA $^{\mathrm{r}}$ rates close to the progenitor wild-type strain, despite their increased tract length [cf. Table 1, RAP1 (plasmid)$350 \mathrm{bp}$ with RAP1 (plasmid)-1110 bp]. An additional indication that telomere tract size is not responsible for the effects of the rap $1^{t}$ mutations on telomere position effects is the finding that rap1-17 cells are completely defective in conferring the repressed state regardless of telomeric length (Table 1).

On the basis of these results, we conclude that loss of the carboxyl terminus of RAP1 in rap1-17 and rap1-18 alleles results in the derepression of telomerically located genes in a process that appears to be independent of either the identity of the telomere $\left(\mathrm{V}_{\mathrm{R}}\right.$ or $\left.\mathrm{VII}_{\mathrm{L}}\right)$, the gene examined (URA3 or $A D E 2$ ), or the length of the telomeric tract.

\section{HML $\alpha$ is partially derepressed in rap1-17 cells}

Given the profound reduction of telomere position effects in rap1-17 alleles, we sought to determine whether $H M L$ silencing is also disrupted in these cells. To directly test for the derepression of $H M L \alpha$, we isolated RNA from wild-type, rap1-17, and sir2 cells and analyzed the expression of $\alpha 1, \alpha 2$, and $\mathbf{2} 2$ transcripts in these cells by Northern analysis (Fig. 4). As expected, wildtype $M A T \alpha$ cells expressed only $\alpha 1$ and $\alpha 2$ transcripts (Fig. 4, lanes 6,7), whereas only MATa cells expressed a2 message (Fig. 4, lanes 1-5). In contrast, $\alpha$ transcripts were detected for all rap1-17 MATa strains tested (Fig. 4, lanes 2-4) at levels close to those found in sir2 MATa cells (Fig. 4, lane 10), indicating that $H M L \alpha$ is transcriptionally derepressed in rap1-17 cells. The derepression of $\alpha$ tran-

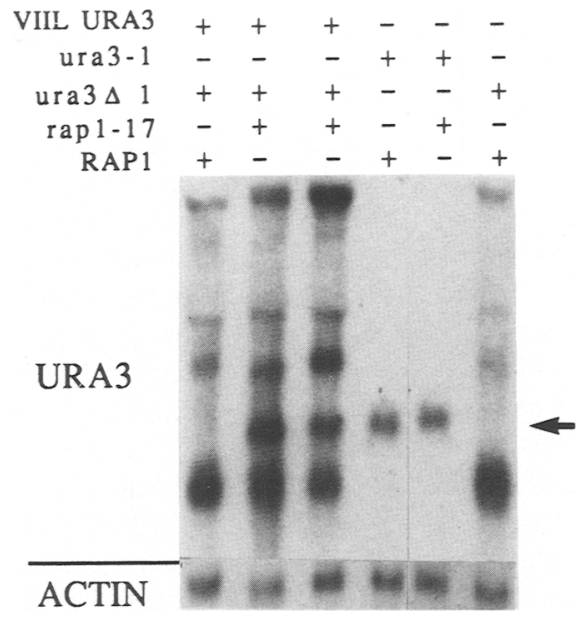

Figure 2. $\operatorname{rap}^{t}$ alleles derepress transcription of URA3marked telomeres. RNA was isolated from rap1-17 and wildtype strains containing either the ura3-1 or ura3 $\Delta 1$ allele at its normal locus in the presence or absence of the URA3-marked $\mathrm{VII}_{\mathrm{L}}$ telomere, and subjected to Northern analysis using a probe to the $U R A 3$ gene. The presence $(+)$ or absence $(-)$ of each of the alleles of $U R A 3$ and $R A P 1$ is indicated at top. In addition to the 800-nucleotide $U R A 3$ transcript, indicated by the arrow, multiple species derived from transcription initiating within the ura3 $31:: T R P 1::$ ura3 $\Delta 1$ duplication were also observed. To measure the relative levels of RNA in each lane, blots were stripped and rehybridized with a probe to actin RNA, and the hybridization signal was quantitated using the $\beta$-scope (Betagen). Control actin mRNA levels in each lane varied by less than twofold. Strains used (in order of lanes) are as follows: AJL401-9c, AJL406-3d, AJL406-4d, AJL401-5a, AJL406-7b, and AJL401-2c. 


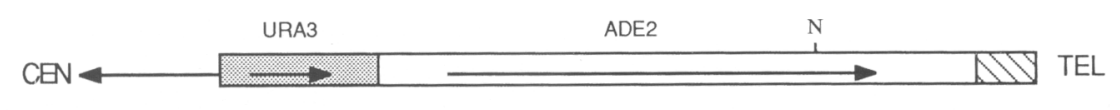

RAP1
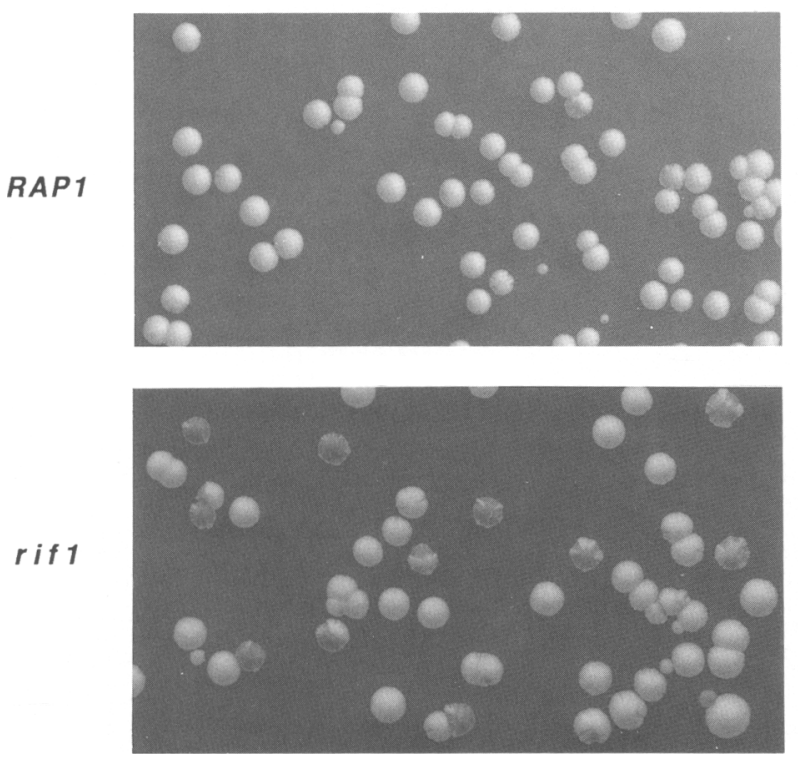
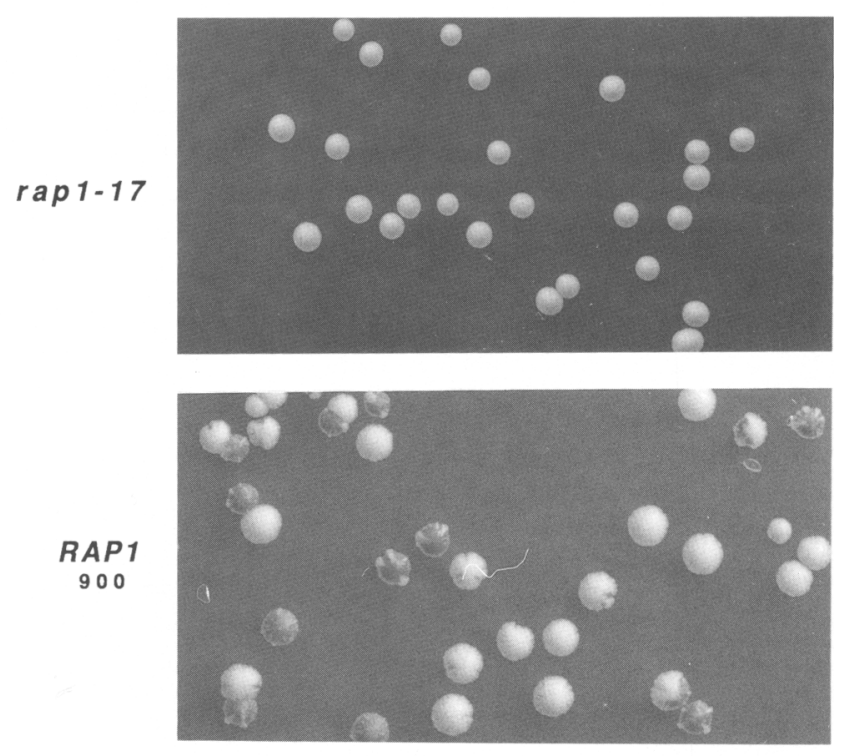

Figure 3. Telomeric ADE2 expression in wild-type, rap1-17, and rif1 strains. Shown are representative samples of wild-type (RAP1,

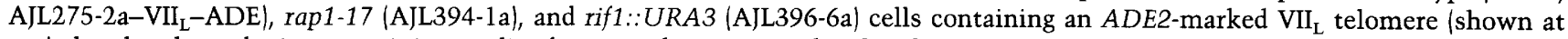
top) plated on low adenine-containing media after nonselective growth. Also shown is an identical plating of wild-type cells inheriting a 900-bp telomeric tract (RAP1 $\left.{ }_{900}, \mathrm{AJL} 412-5 \mathrm{a}\right), 600 \mathrm{bp}$ longer than the 300-bp tract found in the progenitor wild-type cells. Identical results were obtained with multiple rap1-17 and rif1::URA3 strains. The direction of transcription is indicated by the arrows within the URA3 and ADE2 genes in the diagram (derived from Gottschling et al. 1990) The position of the NdeI site (N) is also indicated.

scripts is fully complemented by a plasmid-borne copy of the RAP1 gene (Fig. 4, lane 5). This derepression of $\alpha 1$ and $\alpha 2$ transcription is $H M L$ specific. Transcription of the $M A T \alpha$ locus is not affected severely by the rap1-17 mutation, with transcript levels increasing by no more than twofold from expected values (Fig. 4, lanes 6-9). The rap1-17 mutation does not significantly derepress HMRa. Both wild-type and rap1-17 cells do not express detectable levels of 2 message.

Consistent with the transcriptional derepression of $H M L \alpha$, the mating efficiency of rap1-17 HML $M A T \mathbf{a}$ $H M R \mathbf{a}$ strains is significantly decreased. Whereas wildtype cells repressed for $H M L \alpha$ expression display high levels of mating $(62 \%)$, rap1-17 cells exhibit 2- to 200fold lower mating efficiencies, with the extent of the decrease varying widely both among different isogenic rap1-17 strains and among different colonies derived from a common rap1-17 progenitor. In contrast, rap1-17 HMLa MATa HMRa strains mate at wild-type efficiencies (data not shown), indicating that derepression of $H M L$ is required for the lowered mating efficiency. As expected, rap1-17 HML $\alpha$ MAT $\alpha$ HMRa cells mate at wild-type efficiencies. These data suggest that $H M L \alpha$, but not $H M R \mathbf{a}$, is partially derepressed in rap1-17 cells.

Increased accessibility of E. coli dam methylase to subtelomeric chromatin in rap1-17 cells

Recent studies have used the accessibility of chromo- somal sequences to dam methylase as an in vivo assay for chromatin structure (Gottschling 1992; Singh and Klar 1992). Two GATC sites have been identified in the URA3 gene that display unique characteristics when placed adjacent to telomeric sequences in wild-type strains (Gottschling 1992; Wright et al. 1992). One site, at the junction between $U R A 3$ and poly $\left(\mathrm{G}_{1-3} \mathrm{~T}\right)$ sequences (Fig. 5, site 1), displays hypersensitivity to methylation, whereas a second site within the coding region of URA3 (Fig. 5, site 2) is only weakly accessible to methylation. The accessibility of site 2 to methylation is regained in strains defective for telomere position effects (e.g., sir2 mutants), suggesting that the formation of a closed chromatin state may be mechanistically linked to the transcriptionally repressed state at the telomere (Gottschling 1992).

Because rap1-17 and sir2 cells display similar levels of URA3 derepression, we tested whether these strains also exhibit similar changes in accessibility to the dam methylase. To this end, a series of isogenic wild-type, rap117 , and sir2 strains were constructed, each of which contained an integrated copy of the $E$. coli dam methylase gene and a $U R A 3$ gene adjacent to either the $\mathrm{V}_{\mathrm{R}}$ or $\mathrm{VII}_{\mathrm{L}}$ telomere. To determine the methylation state of site 2, DNA was digested first with HindIII and BamHI, releasing a 1.15-kb internal fragment containing the ura3-1 gene (fragment A) and a 1.10-kb telomeric URA3-containing fragment (fragment $\mathrm{B}$ ), and subsequently cleaved with MboI, DpnI, or Sau3AI (Fig. 5). MboI and DpnI 


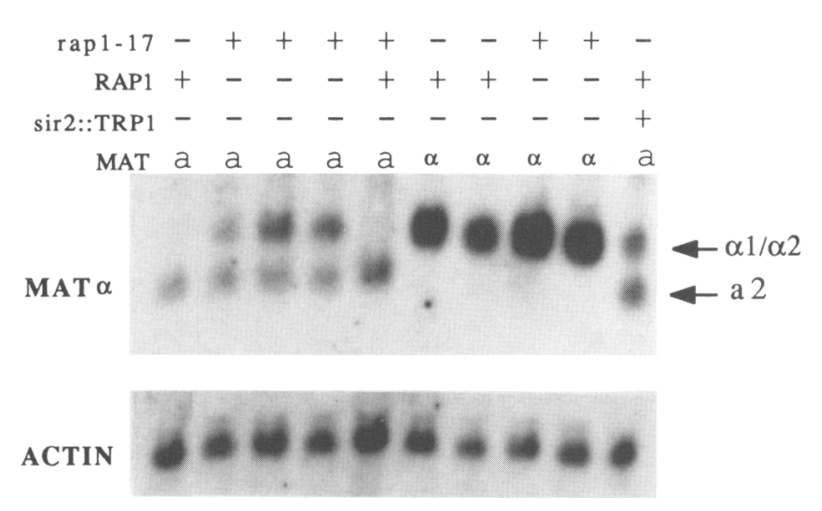

Figure 4. Transcription of $H M L \alpha$ is derepressed in rap1-17 cells. RNA was isolated from MATa and MAT $\alpha$ derivatives of wild-type $R A P 1$, rap1-17, and sir2::TRP1 cells, and the resulting blots were probed with a restriction fragment containing the $M A T \alpha$ gene. This probe hybridizes to both the $\alpha 1$ and $\alpha 2$ transcripts (expressed at the MAT $\alpha$ locus) as well as the partially homologous a 2 transcript (expressed at the MATa locus). The presence $(+)$ or absence $(-)$ of rap1 and sir2 alleles and the mating type of each strain is shown above each lane. (Top) The relative abundance of the 740 -nucleotide $\alpha$ transcripts $(\alpha 1 / \alpha 2)$ and the 590-nucleotide a2 transcript. As a loading control, blots were stripped and hybridized with a probe to actin mRNA (bottom). Signals were quantitated using the $\beta$-scope (Betagen). $\alpha 1$ / $\alpha 2$ Levels were normalized to actin mRNA levels and expressed relative to the MAT $\alpha$ wild-type control in lane 6 . Relative values are as follows: (Lane 2) 0.23; (lane 3) 0.46; (lane 5) 0.42; (lane 6) 1.0; (lane 7) 1.4; (lane 8) 2.5; (lane 9) 1.8; (lane 10) 0.35. The relative abundance of the a 2 transcript did not differ between wild-type and rap1-17 MATa cells, and the a2 transcript could not be detected in either wild-type or rap1-17 MAT $\alpha$ cells. Taking into account the expected derepression of $H M L \alpha$ in rap 1-17 $M A T \alpha$ cells, we estimate that the expression of $\alpha 1$ and $\alpha 2$ at the $M A T \alpha$ locus is increased by no more than twofold in rap1-17 cells. The mating efficiencies of the MATa strains shown, relative to W303a, are 0.55 (AJL274-4c), 0.12 (AJL278-4d), 0.03 (AJL369-4d), and 1.15 (AJL369-4d/RAP1). Strains used are as follows (in order of lanes): W303a, AJL274-4c, AJL278-4d, AJL369-4d, AJL369-4d/RAP1, W303 $\alpha$, AJL274-3c, AJL278-1a, AJL274-1c, AJL387-5a $\Delta$ sir2.

cleave at fully unmethylated and fully methylated GATC sites, respectively, whereas Sau3AI cleaves GATC regardless of its methylation state. Telomere-specific inaccessibility to methylation is indicated by a preferential retention of fragment B relative to fragment A after digestion with $D p n I$.

Wild-type cells marked at the $\mathrm{VII}_{\mathrm{L}}$ telomere gave results consistent with previous studies (Gottschling 1992; Fig. 5, upper left). Under conditions in which the internal fragment A is efficiently cleaved by $D p n I$, 70$95 \%$ of the telomeric fragment B is resistant to cleavage by DpnI, consistent with a high level of protection against methylation at the telomere. rap1-17 cells produced a markedly different pattern (Fig. 5, right). Only a subpopulation of fragment $B$ molecules $(\sim 15-30 \%)$ is resistant to cleavage by $D p n I$, indicating that the rap1-17 mutation decreases the susceptibility of site 2 to methylation. However, while less resistant than wild-type, fragment $B$ reproducibly shows less accessibility to the methylase than fragment $A$. These data suggest that elements of structure responsible for the telomere-specific protection are maintained in rap1-17 cells. At the $V_{R}$ telomere, which confers weaker position effects on URA3 than the $\mathrm{VII}_{\mathrm{L}}$ telomere, both wild-type and rap117 cells display levels of telomere-specific protection similar to that found in rap1-17 cells at the $\mathrm{VII}_{\mathrm{L}}$ telomere (data not shown).

It was surprising that telomere-specific protection against methylation was observed in a fraction of rap117 cells despite the phenotypically complete derepression of the telomeric URA3 gene. To examine whether this property is shared by other mutations affecting telomere position effects, we compared the protection patterns of rap1-17 and sir2 mutants containing telomeres marked at $\mathrm{VII}_{\mathrm{L}}$ (Fig. 5, lower left). In spite of the identical phenotypes displayed by rap 1-17 and sir2 cells in the FOA assay, sir2 cells exhibit a complete loss of telomere-specific protection against methylation. In these mutants, fragment $B$ retains only a residual level of protection also found at the internal locus. An identical result was obtained in sir2 mutants marked at $\mathrm{V}_{\mathrm{R}}$ (data not shown). Hence, whereas both sir2 and rap1-17 mutations cause significant changes in subtelomeric chromatin structure, rap1-17 cells retain a significant degree of protection against the dam methylase.

We note that in both wild-type and rap1-17 cells, the amount of fragment B generated after cleavage with HindIII and $D p n I$ is only slightly less $(\sim 60-95 \%)$ than that retained after triple digestion with HindIII, DpnI, and BamHI. Because BamHI quantitatively cleaves at site 1 , these results indicate that the majority of molecules resistant to DpnI at site 2 are cleaved by this enzyme at site 1 , suggesting that site 1 is highly accessibile to dam methylase in both wild-type and mutant cells.

\section{Loss of RIF1 enhances telomere position effects}

One possible cause for the derepression of telomeric genes observed in rap $1^{t}$ cells is the absence of specific contacts between the carboxyl terminus of RAP1 and other proteins involved in this process. One candidate for such a factor is RIF1, identified in a genetic screen for carboxyl terminus-interacting proteins (Hardy et al. 1992b). Deletion of the RIF1 gene results in two phenotypes: derepression of silencing in strains containing $H M R \triangle A$ silencers and elongation of the telomeric tract by $150-300$ bp (Hardy et al. 1992b; see Fig. 6). Although phenotypically distinct from rap $1^{t}$ alleles with regard to telomere length and stability, the inability of RIF1 to interact with the Rap $1^{\mathrm{t}}$ protein may nonetheless be partially or completely responsible for their effects on telomere position effects.

To test this possibility, we analyzed the red/white sectoring patterns in a strain carrying a rif $1:: U R A 3$ null allele and a subtelomeric $A D E 2$ gene at chromosome $\mathrm{VII}_{\mathrm{L}}$. Strains carrying the rif1::URA3 allele sectored at high frequency (Fig. 3, lower left), with $31 \%$ of cells forming white colonies with red sectors. Nonetheless, 
VIIL TEL
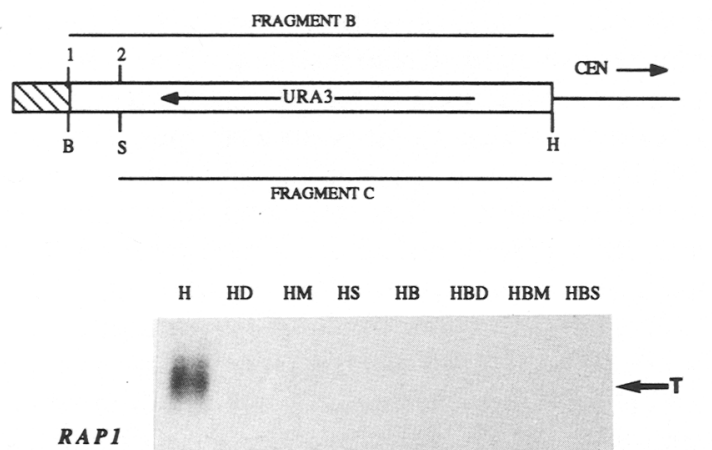

RAP 1

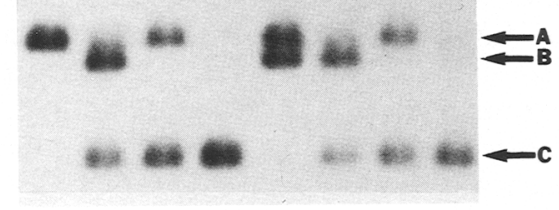

H HD HM HS HB HBD HBM HBS

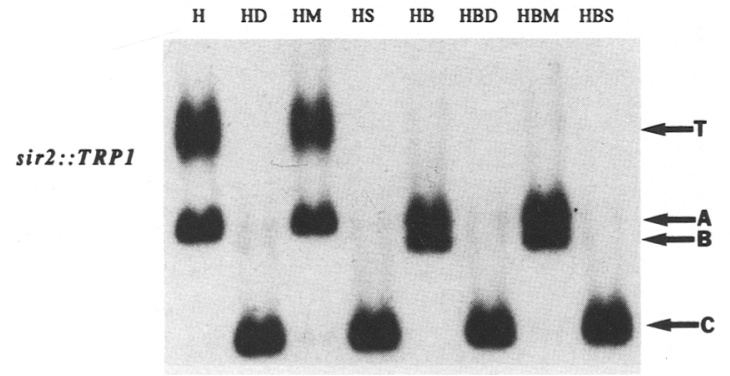

ura 3-1 INTERNAL

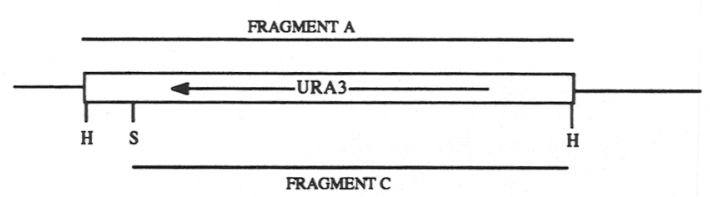

H HD HM HS HB HBD HBM HBS

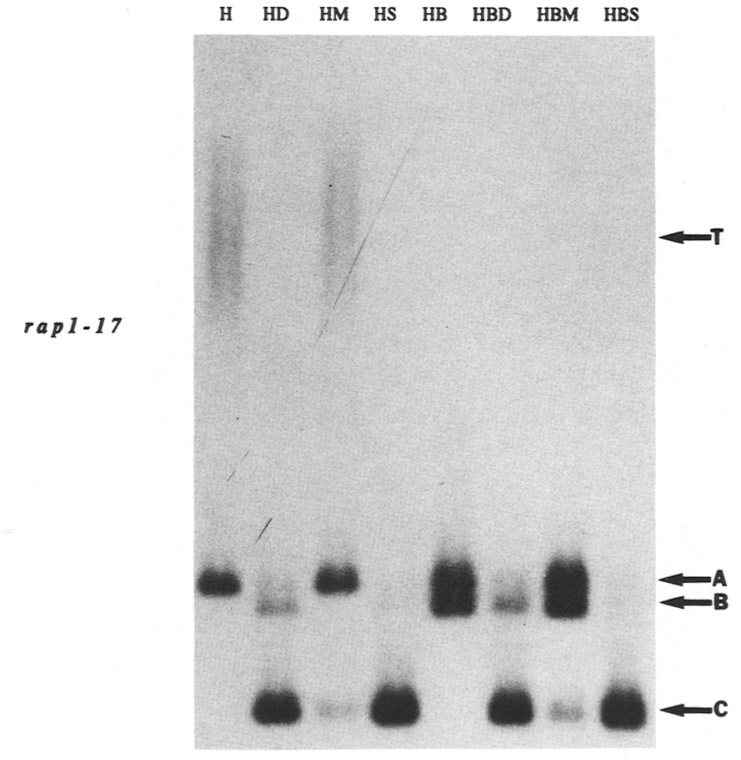

Figure 5. Reduced accessibility of telomeric chromatin to E. coli dam methylase in rap1-17 mutant cells. (Top) Diagram of the structure of the URA3 gene at the $\mathrm{VII}_{\mathrm{L}}$ telomere and the ura3-1 gene at the internal locus (derived from Wright et al. 1992). Diagram designations: (1) The GATC site present at the junction between telomeric sequences (hatched box) and URA3 sequences; (2) the GATC site present within the coding sequence of the $U R A 3$ gene at $\mathrm{VII}_{\mathrm{L}}$. The GATC sequence at site 1 overlaps a BamHI restriction site. The sources of fragments $\mathrm{A}, \mathrm{B}$, and $\mathrm{C}$ are shown adjacent to the relevant restriction sites. The direction of $U R A 3$ transcription is shown by the arrow. (Bottom) DNAs isolated from wild-type (RAP1, AJL387-5a), rap1-17 (AJL391-1c), and sir2::TRP1 (AJL387$5 a \Delta$ sir2) cells were digested with the restriction enzymes indicated above each lane, and Southern blots were probed with URA3 sequences. The positions of fragments $\mathrm{A}, \mathrm{B}$, and $\mathrm{C}$ are indicated by arrows at right. The position of the telomeric HindIII fragment is also indicated by an arrow $(T)$. The sir2::TRP1 panels were overexposed to demonstrate the absence of any telomere-specific protection in these cells. These results were reproduced in multiple wild-type, rap1-17, and sir2 strains. Abbreviations used are (H) HindIII; $(B)$ BamHI; (S) Sau3A1; (D) DpnI; (M) MboI; (TEL) telomere; (CEN) centromere.

rif1::URA3 cells displayed a sectoring phenotype distinct from wild-type. Two classes only rarely found in wild-type cells, red colonies with white sectors and unsectored red colonies, were found at elevated frequencies ( $10 \%$ each). Furthermore, the frequency of white colonies with red sectors was reproducibly two- to three-fold higher than in wild-type cells. In contrast, neither wildtype cells nor rif1 mutants displayed red/white sectoring patterns when $A D E 2$ was introduced at a chromosomeinternal position at HIS4 (data not shown). Hence, elimination of RIF1 association with the carboxyl terminus of RAPl cannot be responsible for the phenotypes observed in rap1-17 and rap1-18 cells. The hyper-repressed state in rif1 cells requires the carboxyl terminus of RAP1, because rif1::URA3 rap1-17 double mutant cells have a phenotype indistinguishable from rap1-17 single mutants ( 1 red sector of 2900 colonies assayed).

\section{Telomere position effects are influenced} by the structure of the telomeric tract

The ability to generate rap1-17 cells with telomeres of varying sizes allowed us to explore the effect of telomere tract size on telomere position effects in wild-type cells (Figs. 3 and 6; Table 2). For these studies, rap1-17 cells containing marked $\mathrm{VII}_{\mathrm{L}}$ or $\mathrm{V}_{\mathrm{R}}$ telomeres of differing tract sizes were crossed with wild-type cells. Wild-type spore colonies inheriting telomeres of differing sizes were then examined for their ability to repress the $A D E 2$ gene at $\mathrm{VII}_{\mathrm{L}}$ or the URA3 gene at $\mathrm{V}_{\mathrm{R}}$. This approach was made possible by the observation that, except for the rapid deletion events noted below, telomeres inherited by wildtype cells decrease in size only slowly $\mid \sim 2$ bp per generation, data not shown). Interestingly, increased telomere tract size appears to enhance the frequency of repressed 


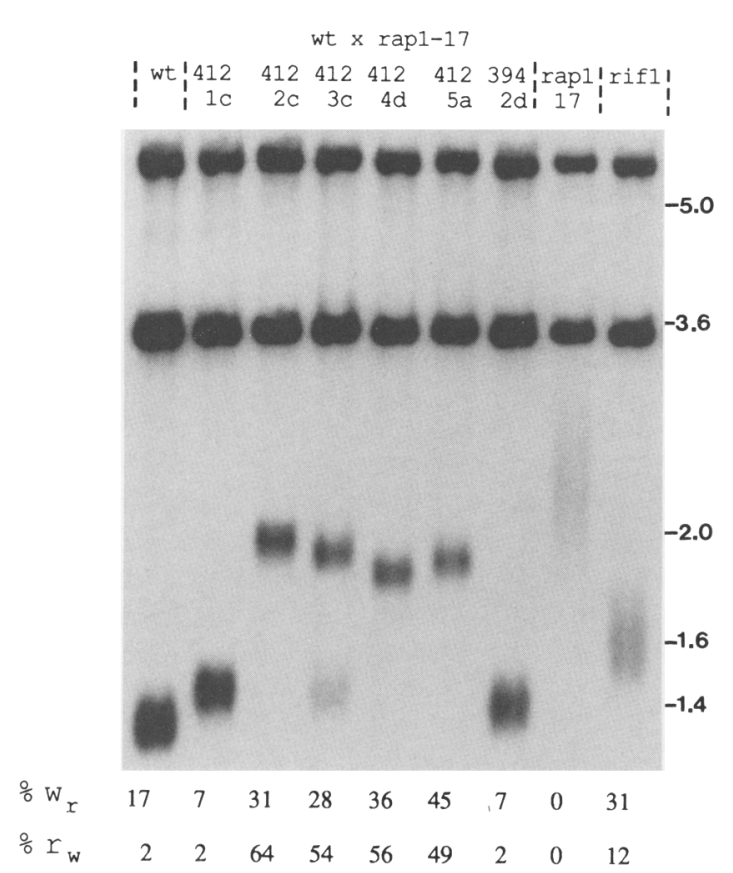

Figure 6. Increased telomere length enhances telomere position effects in wild-type cells. The telomeric fragment sizes of wild-type, rif1, and rap1-17 strains carrying the ADE2-marked $\mathrm{VII}_{\mathrm{L}}$ telomere are displayed together with quantitation of their sectoring patterns. (wt) The original wild-type strain (AJL2752a-VII $-\mathrm{ADE}$ ) carrying the $A D E 2$-marked $\mathrm{VII}_{\mathrm{L}}$ telomere. AJL394-2d is a wild-type spore colony derived from a cross between AJL275-2a-VII $-\mathrm{ADE}$ and an unmarked rap1-17-containing strain. AJL412-1c, $-2 c,-3 c,-4 d$, and $-5 a$ are wild-type spore colonies derived from a cross between an unmarked wild-type strain and a rap1-17 strain carrying elongated $A D E 2$-marked telomeres. ADE2-marked rap1-17 (AJL394-1d) and rif1::URA3 (AJL395-1d) mutant cells are also shown at right. DNAs isolated from these strains were digested with $N d e I$, which distinguishes between the internal and telomeric $A D E 2$ alleles (see Fig. 3), and the resulting blots hybridized to an $A D E 2$ probe. The two highmolecular-mass species reflect subtelomeric and internal fragments of $A D E 2$. The percentages of each population displaying white colonies with red sectors $\left(\% \mathrm{w}_{\mathrm{r}}\right)$ and red colonies with white sectors $\left(\% \mathbf{r}_{\mathbf{w}}\right)$ are shown below the autoradiograph. Sample sizes for these genotypically wild-type strains in lanes 1-7 are $3240,985,812,793,831,690$, and 1095 , respectively. The data for the rap1-17 and rif1 lanes are derived from multiple strains (including the strains displayed) representing cumulative sample sizes of $>5000$ and 868 , respectively. Size markers (in $\mathrm{kb}$ ) are displayed at right.

cells. Wild-type cells inheriting an $A D E 2$-marked $\mathrm{VII}_{\mathbf{L}}$ telomere $800-900 \mathrm{bp}$ in length exhibited an elevated level of both white colonies with red sectors and red colonies with white sectors (Fig. 3, lower right; Fig. 6, $412-2 c, 412-3 c, 412-4 d$, and $412-5 a)$. The vast majority of colonies are sectored in these strains. A similar effect is found in rif1 mutant cells inheriting elongated telomeres from rap1-17 cells, with the frequency of repression exceeding that found in rif1 cells (data not shown). The hyper-repressed state is dependent on the presence of elongated telomeres. Wild-type spore colonies inheriting telomeres of approximately wild-type length $1300-350$ bp) from the same cross have sectoring frequencies close to wild-type (Fig. 6, 412-1c). Similarly, wild-type spore colonies containing tracts approximately wild-type in length derived from the reciprocal cross, between a wildtype strain containing the $A D E 2$-marked telomere and an unmarked rap1-17 strain, also exhibited sectoring frequencies close to wild-type (Fig. 6, 394-2d). The hyperrepressed phenotype is never observed among progeny from crosses between marked and unmarked wild-type strains (data not shown).

An analogous effect was observed at the URA3marked $\mathrm{V}_{\mathrm{R}}$ telomere (Table 2, top). Increased telomere tract length at the $V_{R}$ telomere enhances the frequency of FOA ${ }^{\mathrm{r}}$ colonies, indicating an increase in repression of the subtelomeric $U R A 3$ gene. Telomeric tracts of $>1.3$

Table 2. Telomere position effects in wild-type cells inheriting elongated $V_{R}$ telomeres

\begin{tabular}{|c|c|c|c|}
\hline $\begin{array}{l}\text { Wild-type } \\
\text { strain }\end{array}$ & $\begin{array}{l}\text { Progenitor } \\
\text { diploid } \\
\text { genotype }\end{array}$ & $\begin{array}{l}\text { Tract } \\
\text { size } \\
\text { (bp) }\end{array}$ & $\begin{array}{l}\text { FOA }^{\mathrm{r}} \text { colonies/ } \\
10^{4} \text { cells }^{\mathrm{a}} \\
\text { (range of values; } \\
\text { number of colonies }\end{array}$ \\
\hline $383-3 \mathrm{c} \mathrm{sl}^{\mathrm{b}}$ & $\begin{array}{l}\text { RAP1/ } \\
\quad \text { rap1-17 }\end{array}$ & 420 & $0.7(0-6.18 ; 10)^{c}$ \\
\hline $392-2 d$ & $\begin{array}{l}\text { RAP1/ } \\
\quad \text { rap1-17 }\end{array}$ & 520 & $14.0(1.5-119 ; 14)$ \\
\hline $392-6 a$ & $\begin{array}{l}\text { RAP1/ } \\
\quad \text { rap1-17 }\end{array}$ & 620 & $1.7(0-27.9 ; 14)^{\mathrm{c}}$ \\
\hline $384-3 a$ & $\begin{array}{l}\text { RAP1/ } \\
\quad \text { rap1-17 }\end{array}$ & 650 & $9.7\{0.78-112 ; 10\}$ \\
\hline $392-1 c$ & $\begin{array}{l}\text { RAP1/ } \\
\quad \text { rap1-17 }\end{array}$ & 670 & $42.0(1.4-820 ; 14)$ \\
\hline $383-3 \mathrm{c} \mathrm{s} 0^{\mathrm{b}}$ & $\begin{array}{l}\text { RAP1/ } \\
\text { rap1-17 }\end{array}$ & 1320 & $320.0(0.55-2448 ; 10)$ \\
\hline 384-1c & $\begin{array}{l}\text { RAP1/ } \\
\text { rap1-17 }\end{array}$ & 1420 & $118.0(111-288 ; 4)$ \\
\hline $384-4 a$ & $\begin{array}{l}\text { RAP1/ } \\
\quad \text { rap1-17 }\end{array}$ & 1420 & $520.0(18.9-2199 ; 10)$ \\
\hline $\begin{array}{l}\text { KL4-2d, } \\
\quad-3 b,-5 b^{d}\end{array}$ & $\begin{array}{l}\text { RAP1/ } \\
\quad R A P 1\end{array}$ & 300 & $110.0(3-650 ; 30)$ \\
\hline $383-3 \mathrm{c} \mathrm{s} 0-1^{\mathrm{e}}$ & & 420 & 0.55 \\
\hline $383-3 \mathrm{c} \mathrm{s0}-3^{\mathrm{e}}$ & & 420 & 0.63 \\
\hline $383-3 \mathrm{c} \mathrm{s} 0-4^{\mathrm{e}}$ & & 1180 & 307 \\
\hline $383-3 c s 0-5^{e}$ & & 1130 & 2448 \\
\hline
\end{tabular}

${ }^{\mathrm{a} F O A^{\mathrm{r}}}$ frequencies (per $10^{4}$ cells), presented as described in $\mathrm{Ta}$ ble 1 , were obtained from a population of cells having the indicated average telomere tract length.

b $383-3 \mathrm{c} \mathrm{s} 1$ is isogenic to $383-3 \mathrm{c}$ s0, and was derived from $383-3 \mathrm{c}$ s0 as a single colony after one round of subculturing $\{\sim 25$ generations).

'For 392-6a, one colony also displayed a complete absence of FOA $^{\mathrm{r}}$ cells $(0 / 23,000$ cells $)$. For $383-3 \mathrm{c} \mathrm{s1}, 2$ of the 10 colonies displayed a complete absence of FOA $^{\mathrm{r}}$ cells $10 / 63,000$ cells in both cases).

dhe data derived from these strains were also presented in Table 1 , line 1 .

e(s0-1, s0-3, s0-4, s0-5) Four of the 10 colonies (having the indicated FOA $^{\mathrm{r}}$ frequencies) used for the derivation of the median FOA $^{\mathrm{r}}$ frequency of $383-3 \mathrm{c}$ s 0 . 
$\mathrm{kb}$ in size have $\mathrm{FOA}^{\mathrm{I}}$ frequencies at or above those found in wild-type, with median values ranging between $1.2 \%$ and $5.2 \%$. Indeed, $33 \%(14 / 44)$ of individual colonies have values at or above the maximum value $(6.5 \%) \mathrm{ob}$ served in the original wild-type cells. In contrast, decreasing tract size to between 400 and 700 bp decreases FOA $^{\mathrm{x}}$ frequencies, with median values ranging from $0.02 \%$ to $0.4 \%$ in different segregants. In contrast to the $\mathrm{V}_{\mathrm{R}}$ telomeres, URA3-marked $\mathrm{VII}_{\mathrm{L}}$ telomeres do not display this variation in frequency, with wild-type values ranging between $25 \%$ and $50 \%$ in all spore colonies, suggesting that chromosomal context may influence the susceptibility of termini to changes in telomere size.

A further indication of a relationship between telomere size and telomere position effects is based on observations of rapid deletion events acting on the elongated telomeres inherited by wild-type cells. We have found previously that single-step deletion events can, at high frequency, eliminate substantial amounts of the elongated telomeric poly $\left(\mathrm{G}_{1-3} \mathrm{~T}\right)$ tracts in rap1-17 cells during mitotic growth (Kyrion et al. 1992). We have recently observed that wild-type cells inheriting elongated telomeres from rap1-17 cells are also sometimes capable of producing telomeres near wild-type length in a similar single-step process (e.g., Fig. 6, 412-3c). Interestingly, the loss of $1 \mathrm{~kb}$ of telomeric tract at the URA3-marked $\mathrm{V}_{\mathrm{R}}$ telomere is associated with a concomitant 500 -fold decrease in the frequency of FOA $^{\mathrm{r}}$ colony formation, even though these cells are otherwise isogenic (Table 2, cf. $383-3 \mathrm{c}$ s0 and $383-3 \mathrm{c} \mathrm{s} 1$ ). The presence of truncated telomeres helps to explain the broad distribution of FOA ${ }^{\mathrm{r}}$ frequencies observed in 383-3c s0, because colonies that displayed reduced $\mathrm{FOA}^{\mathrm{r}}$ frequencies (Table 2, s0-1 and s0-3) also exhibited shortened telomeres (Table 2). A similar effect was observed at $A D E 2$-marked $\mathrm{VII}_{\mathrm{L}}$ telomeres. Following rapid deletion at the $\mathrm{VII}_{\mathrm{L}}$ telomere (e.g., Fig. 6, 412-3c), wild type cells inheriting only the deleted species lost the hyper-repressed phenotype and exhibited wild-type sectoring frequencies (data not shown). These data indicate that changes in telomere size significantly influence telomere position effects in yeast.

\section{Discussion}

Previously, we have demonstrated that rap $1^{t}$ alleles produce truncated RAP1 molecules that, while capable of binding specifically to DNA, are missing the carboxyterminal 144-165 amino acids (Kyrion et al. 1992). In vivo, these truncated forms of RAP1 result in telomere elongation and instability, slow growth rate, and high rates of chromosome loss and nondisjunction, suggesting that the carboxyl terminus of RAP1 plays a critical role in regulating telomere and chromosome stability. In this paper, we demonstrate that the carboxy-terminal domain of RAP1 also plays a critical role in regulating telomere-specific position effects on transcription and chromatin structure in yeast. This conclusion is based on two lines of evidence. First, truncation of the carboxyterminal 165 or 144 amino acids of RAP1 in the rap1-17 and rap1-18 alleles results in the inability of telomeres to confer a transcriptionally repressed state onto adjacent polymerase II-transcribed genes. This phenotype is not the simple consequence of increased telomere tract length, because cells wild-type for RAP1 that inherit elongated telomeres regain high levels of repression.

The second observation that argues for a critical role of the carboxyl terminus of RAPl in telomeric suppression is the increased accessibility of subtelomeric chromatin to dam methylase in rap1-17 alleles. The level of site 2 methylation at telomeric $U R A 3$ genes is reduced significantly relative to wild-type. In this regard, the phenotype of this rap1 mutant is similar to strains containing the sir2 and sir 4 mutations, which display a complete loss of telomere-specific protection (Fig. 5; Gottschling 1992). However, unlike sir2 mutants, elements of wildtype chromatin are still maintained in at least a fraction of rap1-17 cells at both $\mathrm{V}_{\mathrm{R}}$ and $\mathrm{VII}_{\mathrm{L}}$ telomeres. Both strands appear to be protected against methylation in both wild-type and rap1-17 cells (data not shown). One explanation for these results is that the fraction of DNA molecules that are methylated directly reflects the proportion of cells retaining protection against methylation. If this were true, protection against methylation could not be a sufficient criterion for forming the repressed state, because $<1 \times 10^{-7}$ cells are phenotypically Ura ${ }^{-}$. Alternatively, all cells in the population may be equally affected by the rap1-17 mutation, but the repressed state is transient and unstable, possibly as a consequence of rapid switching between chromatin conformations.

The majority of the cells assayed in wild-type, rap1-17, and sir2 cells are in the derepressed state at the $\mathrm{V}_{\mathrm{R}}$ telomere. Curiously, the nature of the derepressed state appears to be qualitatively different in sir2 cells than in either wild-type or rap1-17 cells, both of which have levels of protection against dam methylase greater than expected on the basis of their $\mathrm{FOA}^{\mathrm{r}}$ frequencies. While confirming that the structure conferring protection against methylation is insufficient for the formation of a stable repressed state, these data raise the possibility that both wild-type and rap1-17 derepressed cells retain elements of the closed chromatin state. In contrast, the effects of the sir2 mutations appear to be more global in nature, eliminating all vestiges of the wild-type state.

Our data indicate that $H M L \alpha$, but not $H M R \mathbf{a}$, is partially derepressed in rap1-17 cells. These results provide the first direct evidence that RAP1 has a function in $H M L$ silencing, a possibility inferred previously from the functional importance of RAPl-binding sites within the $H M L$ silencer (Mahoney et al. 1991). We note that different cells in a population vary widely in mating efficiency. This phenotype is somewhat similar to the behavior of sir1 mutants (Pillus and Rine 1989). The SIR1 gene product has been shown to be important for the establishment, but not maintenance, of the repressed state at $H M L \alpha$. Whether RAPl plays a similar role remains to be determined.

It is noteworthy that rap1-17 mutations affect $H M L \alpha$ despite the functional redundancy present within the $H M L$ silencer elements. Deletion of either the E or I 
silencer element has no effect on silencing (Mahoney and Broach 1989). Furthermore, deletion of the RAP1binding site in the $\mathrm{E}$ box reduces mating efficiency only in the absence of the I silencer (Mahoney et al. 1991). One possible explanation for this paradox is that the weak RAP1-binding site found previously in the I element (Hofmann et al. 1989) may act as a redundant element in $H M L$ silencing, so that occupation of the RAP1binding sites of both $\mathrm{E}$ and I elements by the terminally truncated RAP1 protein results in a loss of silencing. Alternatively, aberrant associations of RAPl with other factors involved in the function of both $\mathrm{E}$ and I silencer elements (e.g., the consensus ARS element-binding complex ORC) may attenuate transcriptional repression. A third possibility is that interaction of the $E$ and I silencers with telomeric RAP1-binding sites normally plays a role in stabilizing $H M L$ repression in wild-type cells. Disruption of this association in the rap1-17 allele might then result in partial loss of $E$ and I redundancy. In this regard, it is interesting that the I element is sufficient for repression when located at its genomic locus, but not when present on a circular plasmid, possibly reflecting an interaction between the I element and the telomere (Feldman et al. 1984; Mahoney and Broach 1989). Whether the participation of RAP1 in $H M L$ silencing is related to its role in telomere position effects remains unknown.

The phenotypes of the rap $1^{t}$ alleles on telomere position effects are most consistent with a direct involvement of RAPl mediated through binding to the telomere. However, some indirect models for the effect of the rap1-17 mutation need to be considered. First, the rap1-17 allele may indirectly influence the expression of another gene important for this process (or, alternatively, hyperactivate the telomerically located gene). However, the fact that transcription of the MAT $\alpha$ gene, which is regulated by RAP1 (Giesman et al. 1991; Kurtz and Shore 1991), is only slightly influenced by the rap1-17 allele makes this possibility unlikely. Second, the slow growth rate of rap $1^{t}$ cells could contribute to the phenotypes observed here. Although we cannot fully exclude this possibility, we note that wild-type cells grown on minimal and complete media, which vary twofold in growth rate, do not differ in position effects. In addition, we have recently identified missense alleles of rap1 that completely derepress telomeric gene expression while not affecting growth rate (C. Liu and A. Lustig, unpubl.). Finally, it is conceivable that a lowered abundance of the Rapl-17 protein influences position effects. This possiblity is unlikely, however, as the levels of DNA-binding (per microgram of extract) are identical in wild-type and rap1-17 extracts over a broad range of substrate concentrations (G. Kyrion and A. Lustig, unpubl.).

The requirement of the carboxy-terminal region of RAP1 in telomere position effects is likely to reflect critical associations with other position-effect-related factors. Consistent with this proposal is that overproduction of the carboxyl terminus of RAP1 also results in a loss of position effects at the telomere, arguing that a limiting factor important for this process is titrated by the plasmid (E. Wiley and V. Zakian, pers. comm.). One candidate for such a factor is the RAP1-interacting protein RIF1, which plays a role in HMRa silencing (Hardy et al. 1992b). However, our studies indicate that loss of RIF1 function actually increases the efficiency of repression. This effect is likely to be a general phenomenon, as an independent study analyzing the effect of rif1 null alleles on telomere position effects at a URA3-marked $\mathrm{VII}_{\mathrm{L}}$ telomere produced similar results (E. Wiley and V. Zakian, pers. comm.). Two models may explain these data. First, RIF1 may normally act to antagonize the formation or stabilization of the repressed state, possibly by competing with a second factor (e.g., one of the SIR gene products) for association with the carboxyl terminus. Such a competition between factors may help to explain the metastable nature of telomere position effects. Second, the longer telomeres present in rif1 cells (Hardy et al. 1992b; see Fig. 6) may enhance position effects analogous to the behavior of wild-type cells inheriting elongated telomeres from rap1-17 cells.

The results presented here provide the first evidence that telomere position effects are sensitive to the structure of the telomere itself. Two overlapping processes appear to influence telomere position effects in wildtype cells. First, position effects at both $\mathrm{VII}_{\mathrm{L}}$ and $\mathrm{V}_{\mathrm{R}}$ telomeres in wild-type cells are exquisitely sensitive to the size of the inherited marked telomere. Longer telomeres increase the frequency of repression. This size dependency is in striking contrast to the decreasing efficiency of position effects with increasing distance from the telomere (Renauld et al., this issue). These data suggest that the efficiency of telomere position effects may be governed by both the distance of the gene from the telomere tract and the length of that tract. Conceivably, telomere size may promote position effects by creating additional binding sites for either RAP1 or other telomere-binding proteins necessary for this process. An alternative, but not mutually exclusive, possibility is that longer telomeres are more capable of forming higher order structures (e.g., DNA loops) that may be important for telomere position effects.

The size dependency of position effects reopens the issue as to whether position effects may be exerted by poly $\left(\mathrm{G}_{1-3} \mathrm{~T}\right)$ tracts at internal positions. A previous study (Gottschling et al. 1990) demonstrated that $80 \mathrm{bp}$ of poly $\left(G_{1-3} T\right)$, while able to repress telomeric genes, did not influence gene expression at an internal site. Given the profound effect of telomere size on position effects, the possibility that longer tracts may repress transcription even at internal sites needs to be reexamined.

Telomere position effects also appear to be influenced by other structural changes occurring in rap1-17 cells, unrelated to telomere size. Wild-type cells inheriting rap1-17 $\mathrm{V}_{\mathrm{R}}$ telomeres of near-wild-type size display a reduced efficiency of $U R A 3$ repression relative to the original wild-type strains. The impact of these changes appears to be telomere specific, with the $U R A 3$ gene at $\mathrm{V}_{\mathrm{R}}$ being far more sensitive to these effects than either the $A D E 2$ or $U R A 3$ gene at $\mathrm{VII}_{\mathrm{L}}$. Although the basis of this effect remains unknown, both its reversibility by in- 
creased tract size and its genetic linkage to the $V_{R}$ telomere (data not shown) suggest that a permanent change in telomere structure or sequence, rather than a mutation in a second gene, is responsible for this reduced efficiency. Such effects occurring in rap1-17 cells may help to explain the observation that in some cases, the efficiency of telomere position effects varies even for tracts of similar size (e.g., Table 2, cf. 392-6a with 392$2 \mathrm{~d})$. Given the effects of both telomere size and structure on telomere position effects, it is likely that the proteinDNA interactions present at the telomere are actively involved in establishing or maintaining the transcriptionally repressed state and, consequently, in governing the chromatin structure of subtelomeric domains.

Permanent changes in telomere structure or sequence, such as those noted above, may contribute to the derepressed state observed in rap1-17 cells. However, it seems unlikely that such effects fully account for the rap1-17 phenotypes, as a fully derepressed state is observed in rap1-17 cells immediately upon inheriting either a $\mathrm{V}_{\mathrm{R}}$ or $\mathrm{VII}_{\mathrm{L}}$ wild-type telomere and does not change regardless of the degree of subculturing or telomere size. We suggest, therefore, that RAPl participates directly in conferring telomere position effects, possibly through facilitating the formation of telomeric chromatin structures essential for this process.

\section{Materials and methods}

\section{Plasmids}

Plasmids pVII-L-URA3-TEL, pV-R-URA3-TEL, padh4::URA3, and pADADE2 $1+1$, used for the construction of telomeric and internal copies of $U R A 3$ and $A D E 2$, have been described previously (Gottschling et al. 1990). pDP6-dam is a LYS2-containing integrating plasmid carrying the $E$. coli dam methylase gene (Gottschling 1992). pKLl was derived from pDP6-dam by insertion of the HIS3 gene into the BgIII site of the LYS2 gene. pJEF1332, a TRP1-containing integrating plasmid carrying the ura3 $\Delta 1$ deletion allele, has been described previously (Boeke et al. 1987).

Plasmid pRS313/RAP1 was derived by cloning an EcoRI$X b a I$ fragment carrying the RAP1 gene into the HIS3-containing centromeric plasmid pRS313 (Sikorski and Hieter 1989). pRS313/rapl-17 was derived in a similar fashion using the EcoRI-XbaI fragment of pRS316 ${ }_{\mathrm{H}} /$ rap1-17 (Kyrion et al. 1992). Plasmid pRS306/his4/ADE2 was constructed by cloning a SalI$B a m H I$ fragment of HIS4 into the polylinker of the URA3-containing integrating plasmid pRS306 (Sikorski and Hieter 1989). The 3.6-kb BamHI fragment containing the ADE2 gene was then cloned into the polylinker of pRS306/his4, creating the plasmid pRS306/his4/ADE2.

\section{Yeast strains and growth}

Methods for yeast growth and manipulations were performed as described (Sherman et al. 1986). The yeast strains used for this study are shown in Table 3 . Unless otherwise indicated, all strains are isogenic to the wild-type strain W303. The structure of the strains described below was confirmed by Southern and (where appropriate) genetic analyses. To construct strains containing the URA3-marked $\mathrm{V}_{\mathrm{R}}$ telomere, and the URA3- and
ADE2-marked $\mathrm{VII}_{\mathrm{L}}$ telomeres, the wild-type strain AJL275-2a, isogenic to $\mathrm{W} 303$, was transformed with linearized pV-RURA3-TEL, pVII-L-URA3-TEL, and pADADE2 $(+)$ as described (Gottschling et al. 1990), giving rise to strains AJL275$2 a-V_{R}, A J L 275-2 a-V_{L}-U R A$, and AJL275-2a-VII - ADE, respectively. Isogenic strains containing an adh4::URA3 disruption on $\mathrm{VII}_{\mathrm{L}}$ (AJL275-2a-adh::URA) were constructed as described (Gottschling et al. 1990).

The rap1-17 and rap1-18 mutations were introduced into strains containing a URA3- or ADE2-marked telomere or a URA3-marked adh4 locus by appropriate crosses with AJL2752a-V $\mathrm{V}_{R}$, AJL275-2a-VII ${ }_{\mathrm{L}}-\mathrm{URA}$ AJL275-2a-VII - -ADE, and AJL275-2a-adh::URA. AJL369-4d/RAP1 was constructed by transforming the rap1-17-containing spore colony AJL369-4d with pRS313/RAP1.

To generate strains carrying the ura3 $\Delta 1$ allele, KL5-5a was transformed with StuI-digested pJEF1332. A transformant, carrying tandem copies of the ura $3 \Delta 1$ gene /generated by gene conversion during integration), was backcrossed to generate a wildtype spore colony (AJL398-5a) containing the ura3 11 allele. This strain was used to generate wild-type and rap1-17 strains carrying both the URA3-marked $\mathrm{VII}_{\mathrm{L}}$ telomere and the ura3 $\Delta 1$ allele.

A sir2::TRP1 null allele was introduced into strains KL4-5b and AJL387-5a as described (Shore et al. 1984). The rif1::URA3 allele was introduced into W303a as described (Hardy et al. 1992b), and subsequently crossed into wild-type and rap1-17 strains containing the $A D E 2$-marked $\mathrm{VII}_{\mathrm{L}}$ telomere. Strains containing both the rif $1:: U R A 3$ allele and the $A D E 2$ gene inserted at the HIS4 locus were identified after sporulation of a diploid derived from a cross between a rif $1:: U R A 3$-containing strain and strain GK30. GK30, containing an integrated copy of $A D E 2$ at the HIS4 locus, was generated by transformation of NheIdigested pRS306/his4/ADE2 into W303 $\alpha$.

To generate rap1-17 HMLa MATa HMRa strains, a rap1-17containing strain was crossed to the nonisogenic $H M L a M A T \mathbf{a}$ $H M R \mathbf{a} H O$ strain K828. Tetrads from this diploid segregated $2: 2$ for slow growth rate, indicating that rap1-17 is penetrant in these backgrounds. Slow-growing colonies that were capable of mating only with an $\alpha$-mating tester strain were identified. Southern analysis of DNA isolated from these candidates was used to identify strains carrying either the $H M L \alpha$ or $H M L a$ allele.

To introduce the E. coli dam methylase gene, pKL1 was linearized by digestion with StuI, which cleaves uniquely within the LYS2 gene, and the DNA was transformed into the rad1containing strain W839-6b. His ${ }^{+}$transformants having the dam methylase gene integrated into the LYS2 locus (W839-6b-dam) were identified and crossed to appropriate strains to generate wild-type and rap1-17 strains containing a URA3-marked $\mathrm{V}_{\mathrm{R}}$ or $\mathrm{VII}_{\mathrm{L}}$ telomere and the methylase gene. The introduction of the dam methylase and rad1 mutations into these strains had no effect on the expression of the telomeric URA3 genes.

To generate wild-type strains having $A D E 2$-marked $\mathrm{VII}_{\mathrm{L}}$ telomeres $800-900$ bp in length, a rap1-17 strain containing a $\mathrm{VII}_{\mathbf{L}}$ telomere of $\sim 1000 \mathrm{bp}$ was crossed to $\mathrm{W} 303 \mathrm{a}$, and the resulting diploid (AJL412) was sporulated. To generate wild-type strains having URA3-marked $\mathrm{V}_{\mathrm{R}}$ telomeres $500-1500$ bp in length, a rap1-17 strain containing a $\mathrm{V}_{\mathrm{R}}$ telomere of $\sim 750$ bp was crossed to W303a, and the resulting diploid (KL3) was sporulated. The rap 1-17 spore colony KL3-1b was subcultured on solid media for four rounds ( $\mathrm{s} 0-\mathrm{s} 4$ ), with each round consisting of $\sim 25$ generations of growth (Kyrion et al. 1992). The average telomere tract lengths of KL3-1b s0, KL3-1b s1, KL3-1b s2, and KL3-1b s4 were $0.85,1.1,1.35,1.45$, and $1.85 \mathrm{~kb}$, respectively. Each strain was crossed to W303a, the resulting diploids (AJL392, AJL383, 
Table 3. Yeast strains

\begin{tabular}{|c|c|}
\hline Strain & Genotype \\
\hline W303a $\mathrm{a}^{\mathrm{a}}$ & MATa RAP1 leu2-3,112 trp1 ade2-1 ura3-1 HIS3 \\
\hline W303 $\alpha^{a}$ & MATa RAP1 leu2-3,112 trp1 ade2-1 ura3-1 his3 \\
\hline AJL275-2a-VR & MATa RAP1 leu2-3,112 trp1 ade2-1 ura3-1 his3 VR::URA3 \\
\hline AJL275-2a-VIIL-URA & MATa RAP1 leu2-3,112 trp1 ade2-1 ura3-1 his3 VIIL::URA3 \\
\hline AJL275-2a-VIIL-ADE & MAT $\alpha$ RAP1 leu2-3,112 trp1 ade2-1 ura3-1 his3 VIIL::URA3/ADE2 \\
\hline AJL275-2a-adh::URA & MATa RAP1 leu2-3,112 trp1 ade2-1 ura3-1 his3 adh::URA3 \\
\hline AJL369-4d & MATa rap1-17 leu2-3,112 trp1 ade2-1 ura3-1 his3 VIIL::URA3 \\
\hline AJL369-4d/RAP1 & MATa rap1-17 RAP1/CEN/HIS3 leu2-3,112 trp1 ade2-1 ura3-1 his3 VIIL::URA3 \\
\hline AJL369-5b & MATa rap1-17 leu2-3,112 trp1 ade2-1 ura3-1 HIS3 VIIL::URA3 \\
\hline AJL399-4b & MATa rap1-18 leu2-3,112 trp1 ade2-1 ura3-1 his3 VIIL::URA3 \\
\hline AJL364-lc & MATa rap1-17 leu2-3,112 trp1 ade2-1 ura3-1 his3 adh::URA3 \\
\hline W839-6b-dam & MATa RAP1 leu2-3,112 trp1 ade2-1 ura3-1 his3 rad1::LEU2 LYS2:dam/HIS3:lys2 \\
\hline KL4-5b & MATa RAP1 leu2-3,112 trp1 ade2-1 ura3-1 his3 rad1::LEU2 LYS2:dam/HIS3:lys2 VR::URA3 \\
\hline KL5-2c & MATa rap1-17 leu2-3,112 trp1 ade2-1 ura3-1 his3 rad1::LEU2 LYS2:dam/HIS3:lys2 VR::URA3 \\
\hline KL5-5a & MATa rap1-17 leu2-3,112 trp1 ade2-1 ura3-1 his3 rad1::LEU2 LYS2:dam/HIS3:lys2 VR::URA3 \\
\hline KL4-5b $\Delta \operatorname{sir} 2$ & MATa RAP1 sir2::TRP1 leu2-3,112 trp1 ade2-1 ura3-1 his3 rad1::LEU2 LYS2:dam/HIS3:lys2 VR::URA3 \\
\hline AJL387-5a & MATa RAP1 leu2-3,112 trp1 ade2-1 ura3-1 his3 rad1::LEU2 LYS2:dam/HIS3:lys2 VILL::URA3 \\
\hline AJL391-1c & MATa rap1-17 leu2-3,112 trp1 ade2-1 ura3-1 his3 rad1::LEU2 LYS2:dam/HIS3:lys2 VIIL::URA3 \\
\hline AJL387-5a $\Delta \sin 2$ & MATa RAP1 sir2::TRP1 leu2-3,112 trp1 ade2-1 ura3-1 his3 rad1::LEU2 LYS2:dam/HIS3:lys2 VIIL::URA3 \\
\hline GK23-1 $b^{b}$ & MATa RAP1/CEN/TRP1 rap1::LEU2 leu2-3,112 trp1 ade2-1 ura3-1 his3 VR::URA3 \\
\hline $\mathrm{P} 17 \mathrm{~s} 4^{\mathrm{b}}$ & MATa rap1-17/CEN/HIS3 rap1::LEU2 leu2-3,112 trp1 ade2-1 ura3-1 his3 VR::URA3 \\
\hline P17 s4D-Pb & MAT $R A P 1 / C E N / T R P 1$ rap $1:: L E U 2$ leu2-3,112 trp1 ade2-1 ura3-1 his3 VR::URA3 \\
\hline AJL398-5a & 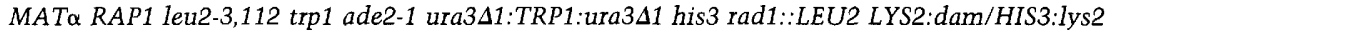 \\
\hline \multirow{2}{*}{ AJL401 } & 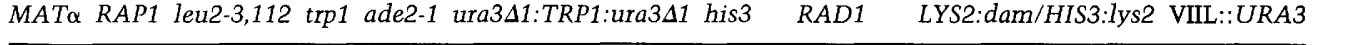 \\
\hline & $\begin{array}{llcc}\text { MATa } & \text { RAP1 leu2-3,112 trp1 ade2-1 } & \text { ura3-1 } & \text { his3 rad1:LEU2 } \\
\text { MATa RAP1 leu2-3.112 trp1 ade2-1 ura3A1:TRP1:ura3A1 HIS3 } & \text { RAD1 }\end{array}$ \\
\hline \multirow{2}{*}{ AJL406 } & \\
\hline & MATа rap1-17 leu2-3,112 trp1 ade2-1 \\
\hline EMPY75 & MATa thr3 met \\
\hline EMPY76 ${ }^{\mathrm{c}}$ & MATa lys1 \\
\hline AJL274-4c, AJL278-4d & MATa rap1-17 leu2-3,112 trp1 ade2-1 ura3-1 HIS3 \\
\hline AJL274-3c $c^{\mathrm{d}}$ & MAT $\alpha$ RAP1 leu2-3,112 trp1 ade2-1 ura3-1 HIS3 \\
\hline AJL274-1c, AJL278-1 $a^{d}$ & MATa rap1-17 leu2-3,112 trp1 ade2-1 ura3-1 HIS3 \\
\hline $\mathrm{K} 828^{\mathrm{e}}$ & HMLa MATa HMRa HO leu2 ura3 cry1 \\
\hline \multirow{2}{*}{ AJL395, AJL396 } & leu2-3,112 trp1 ade2-1 ura3-1 HIS3 VIIL::URA3/ADE2 \\
\hline & MATa $R A P 1$ rif1::URA3 leu2-3,112 trp1 ade2-1 ura3-1 his3 \\
\hline \multirow{2}{*}{ AJL394/AJL412 } & MATa RAP1 leu2-3,112 trp1 ade2-1 ura3-1 HIS3 VIIL::URA3/ADE2 \\
\hline & MATa rap1-17 leu2-3,112 trp1 ade2-1 ura3-1 his3 \\
\hline KL3-1b & MAT $\alpha$ rap1-17 leu2-3,112 trp1 ade2-1 ura3-1 his3 VR::URA3 \\
\hline AJL392 & $\mathrm{KL} 3-1 \mathrm{~b}$ s0 $\times \mathrm{W} 303 \mathrm{a}$ \\
\hline AJL383 & KL3-1b s1 × W303a \\
\hline AJL384 & KL3-1b s2 $\times$ W303a \\
\hline AJL386 & KL3-1b s $4 \times$ W303a \\
\hline
\end{tabular}

${ }^{a}$ Strain from Kurtz and Shore (1991).

${ }^{b}$ The wild-type strains GK23-1b and P17 s4D-P, although genotypically identical, differ by 750 bp in tract length at the $V_{R}-m_{a r k e d}$ telomere.

${ }^{\mathrm{c} G i f t}$ of Dr. Eric Phizicky (University of Rochester, New York).

${ }^{\mathrm{d}}$ From Kyrion et al. (1992).

${ }^{\text {eGift }}$ of Dr. Amar Klar (NCI, Frederick, MD); this strain also has mutations in the HIS2 and/or HIS4 genes.

${ }^{\mathrm{f}} \mathrm{AJL} 394$ and AJL412 differ only in the tract length of the ADE2-marked VII $\mathrm{L}_{\mathrm{L}}$ telomere. AJL394 was derived by crossing a wild-type strain carrying an $A D E 2$-marked $\mathrm{VII}_{\mathrm{L}}$ telomere to an unmarked rap1-17 strain; AJL412 was derived by crossing a rap1-17 strain carrying elongated $A D E 2$-marked $\mathrm{VII}_{\mathrm{L}}$ telomeres to an unmarked wild-type strain (see Materials and methods).

AJL384, and AJL386, respectively/ were sporulated, and wildtype spore colonies, containing $V_{R}$ telomeres of differing sizes, were identified.

\section{Telomere tract length determination}

The telomere tract length of URA3-marked $\mathrm{V}_{\mathrm{R}}$ and $\mathrm{VII}_{\mathrm{L}}$ telomeres were determined as described (Kyrion et al. 1992). The tract lengths of $A D E 2$-marked $\mathrm{VII}_{\mathrm{L}}$ telomeres were determined by probing Southern blots of NdeI-digested DNA with a 3.6-kb $B a m H I$ fragment carrying the ADE2 gene. NdeI cleaves $\sim 750$ bp from the $A D E 2 /$ poly $\left(\mathrm{G}_{1-3} \mathrm{~T}\right)$ junction.

Plasmid shuffles

Following transformation of GK23-1b with pRS313/rap1-17, strains were identified that retained only the pRS313/rapl-17 
plasmid. One such strain (P17) was subcultured and cells containing a $\mathrm{V}_{\mathrm{R}}$ telomere tract length of $1.5 \mathrm{~kb}(\mathrm{P} 17 \mathrm{~s} 4)$ were transformed with $\mathrm{pD130}$, containing a wild-type copy of $R A P 1$ on a TRP1 centromeric plasmid (Kurtz and Shore 1991). Following nonselective growth, strains were identified that contain only the wild-type copy of RAP1 (P17s4D-P) while retaining the elongated telomeres from rap1-17. We note that the lower level of repression observed when a wild-type $R A P 1$ gene is located in a plasmid, rather than chromosomal, context is the probable consequence of altered expression of the plasmid-encoded product.

\section{Assays for transcriptional repression}

FOA assay To assay wild-type Ura ${ }^{-}$frequencies, 4 to $10 \mathrm{col}-$ onies were grown on YPD media at $25^{\circ} \mathrm{C}$ to a diameter of $1 \mathrm{~mm}$, and the entire colony was suspended and diluted in SC media. Following appropriate dilutions, cells were spread onto FOA plates and incubated at $30^{\circ} \mathrm{C}$ for $3-5$ days. To assay $\mathrm{Ura}^{-}$frequencies in rap1-17, rap1-18 and sir2::TRP1 cells, 10 colonies were grown to a diameter of $2 \mathrm{~mm}$ and the entire colony (containing $1 \times 10^{7}$ to $4 \times 10^{7}$ cells), following suspension, was plated onto two FOA plates. Plates were incubated at $30^{\circ} \mathrm{C}$ for 5-7 days. In each case, total cell counts were determined after plating appropriate dilutions onto YPD media. The data are presented as median values together with the range of values observed. The repressed state present in both wild-type and rap118 cells is reversible. FOA ${ }^{r}$ cells switch to the $\mathrm{Ura}^{+}$phenotype at high frequencies during growth on nonselective media.

ADE2 visual assay Wild-type, rap1-17, rif1::URA3, and rap1-17 rif1::URA3 strains carrying the $\mathrm{VII}_{\mathrm{L}}$ telomere (or his4 locus) marked by the $A D E 2$ gene were grown at $30^{\circ} \mathrm{C}$ for 2 days. Cells were suspended in SC media, diluted, and plated onto SC media containing limiting concentrations of adenine (Hieter et al. 1985). Wild-type and rif1::URA3 strains were grown at $30^{\circ} \mathrm{C}$ for 3 days and then shifted to $25^{\circ} \mathrm{C}$ for full color development. rap 1-17 and rap 1-17 rif1::URA3 strains were grown at $30^{\circ} \mathrm{C}$ for 5 days before being shifted to $25^{\circ} \mathrm{C}$.

Transcriptional analysis RNA was isolated by standard methods after growth in YPD at $25^{\circ} \mathrm{C}$. Following electrophoresis of RNA on a $1.5 \%$ formaldehyde-agarose gel, Northern analysis was carried out using either a PstI-SmaI fragment derived from the URA3 gene or a $4.0-\mathrm{kb}$ HindIII fragment carrying the $M A T \alpha$ gene as a probe.

\section{dam methylation analysis}

DNA was isolated from dam methylase-containing wild-type, rap1-17, and sir2 cells grown in rich (YPD) media at $25^{\circ} \mathrm{C}$, and digested as described in the text, and the resulting blots were probed with the PstI-SmaI fragment of URA3. This fragment has identical homology to both the telomeric and internal copies of URA3 (see Fig. 5). The relative hybridization signals of the fragments were estimated using the $\beta$-scope (Betagen). Under some conditions of growth, yeast strains carrying the dam methylase exhibited a generalized decrease in methylation, leading to an overall increase in the abundance of DpnI-resistant fragments. We therefore used both the DpnI digestion pattern of yeast DNA and the ability of the internal fragment A to be fully cleaved by $D p n I$ as internal controls for cellular dam methylase activity.

\section{Quantitative mating assays}

Quantitative mating assays were carried out as described previously (Dutcher and Hartwell 1982), using MATa and MAT $\alpha$ derivatives of wild-type and rap1-17-containing strains, and the tester strains EMPY 75 and EMPY 76. The wild-type strain W303a was included in each trial as a control. As an additional control, six HMLa MATa HMRa and four HML $\alpha$ MATa HMRa spore colonies derived from the same diploid strain were also tested. Whereas $H M L \alpha$ strains showed significant decreases in mating, HMLa derivatives always exhibited wild-type mating efficiencies.

\section{Acknowledgments}

We thank Dan Gottschling, David Shore, Jef Boeke, Phil Hieter, Amar Klar, and Rodney Rothstein for providing plasmids and yeast strains, and Emily Wiley, Virginia Zakian, Dan Gottschling, and David Shore for communicating results prior to publication. We also thank Titia deLange, Dale Dorsett, and E. B. Hoffman for valuable comments on the manuscript, and Ken Boakye for expert technical assistance. These studies were supported by a grant from the National Science Foundation (DMB 9120208) and our Cancer Center support grant (NCI-P30CA-08748).

The publication costs of this article were defrayed in part by payment of page charges. This article must therefore be hereby marked "advertisement" in accordance with 18 USC section 1734 solely to indicate this fact.

\section{References}

Aparicio, O., B. Billington, and D. Gottschling. 1991. Modifiers of position effect are shared between telomeric and silent mating-type loci in S. cerevisiae. Cell 66: 1279-1287.

Bell, S. and B. Stillman. 1992. ATP-dependent recognition of eukaryotic origins of DNA replication by a multiprotein complex. Nature 357: 128-134.

Boeke, J., J. Trueheart, G. Natsoulis, and G. Fink. 1987. 5-fluoroorotic acid as a selective agent in yeast molecular genetics. Methods Enzymol. 154: 164-175.

Brand, A., G. Micklem, and K. Nasmyth. 1987. A yeast silencer contains sequences that can promote autonomous plasmid replication and transcriptional activation Cell 51: 709-719.

Buchman, A., W. Kimmerly, J. Rine, and R. Kornberg. 1988. Two DNA-binding factors recognize specific sequences at silencers, upstream activating sequences, autonomously replicating sequences, and telomeres in Saccharomyces cerevisiae. Mol. Cell. Biol. 8: 210-225.

Conrad, M., J. Wright, A. Wolf, and V. Zakian. 1990. RAPl protein interacts with yeast telomeres in vivo: Overproduction alters telomere structure and decreases chromosome stability. Cell 63: 739-750.

Dutcher, S. and L. Hartwell. 1982. The role of Saccharomyces cerevisiae $C D C$ genes in nuclear fusion. Genetics 100: 175184.

Feldman, J., J. Hicks, and J. Broach. 1984. Identification of the sites required for repression of a silent mating type locus in yeast. I. Mol. Biol. 178: 815-834.

Giesman, D., L. Best, and K. Tatchell. 1991. Role of RAP1 in the regulation of the MAT $\alpha$ locus. Mol. Cell. Biol. 11: 10691079.

Gottschling, D. 1992. Telomere-proximal DNA in Saccharomyces cerevisiae is refractory to methyltransferase activity in vivo. Proc. Natl. Acad. Sci. 89: 4062-4065.

Gottschling, D., O. Aparicio, B. Billington, and V. Zakian. 1990. Position effect at $S$. cerevisiae telomeres: Reversible repression of PollI transcription. Cell 63: 751-762.

Hardy, C., D. Balderes, and D. Shore. 1992a. Dissection of a carboxy-terminal region of the yeast regulatory proein RAP1 
with effects on both transcriptional activation and silencing. Mol. Cell. Biol. 12: 1209-1217.

Hardy, C., L. Sussel, and D. Shore. 1992b. A RAP1-interacting protein involved in transcriptional silencing and telomere length regulation. Genes \& Dev. 6: 801-814.

Hieter, P., C. Mann, M. Snyder, and R. Davis. 1985. Mitotic stability of yeast chromosomes: A colony color assay that measures nondisjunction and chromosome loss. Cell 40: 381-392.

Hofmann, J., T. Laroche, A. Brand, and S. Gasser. 1989. RAP-1 factor is necessary for DNA loop formation in vitro at the silent mating type locus $H M L$. Cell 57: 725-737.

Klein, F. T. Laroche, M. Cardenas, J. Hoffmann, D. Schweizer, and S. Gasser. 1992. Localization of RAP1 and topoisomerase II in nuclei and meiotic chromosomes of yeast. $J$. Cell. Biol. 117: 935-948.

Kurtz, S. and D. Shore. 1991. RAP1 protein activates and silences transcription of mating-type genes in yeast. Genes \& Dev. 5: 616-628.

Kyrion, G., K. Boakye, and A. Lustig. 1992. C-terminal truncation of RAPl results in the deregulation of telomere size, stability, and function in Saccharomyces cerevisiae. Mol. Cell. Biol. 12: 5159-5173.

Laurenson, P. and J. Rine. 1992. Silencers, silencing and heritable transcriptional states. Microbiol. Rev. 56: 543-560.

Levis, R., T. Hazelrigg, and G. Rubin. 1985. Effects of genomic position on the expression of transduced copies of the white gene in Drosophila. Science 229: 558-561.

Longtine, M., N. Wilson, M. Petracek, and J. Berman. 1989. A yeast telomere binding activity binds to two related telomere sequence motifs and is indistinguishable from RAPl. Curr. Genet. 16: 225-239.

Lustig, A., S. Kurtz, and D. Shore. 1990. Involvement of the silencer and UAS binding protein RAPl in regulation of telomere length. Science 250: 549-553.

Mahoney, D. and J. Broach. 1989. The HML mating-type cassette of Saccharomyces cerevisiae is regulated by two separate but functionally equivalent silencers. Mol. Cell. Biol. 9: 4621-4630.

Mahoney, D., R. Marquardt, G.-J. Shei, A. Rose, and J. Broach. 1991. Mutations in the HMLE silencer of Saccharomyces cerevisiae yield metastable inheritance of transcriptional repression. Genes \& Dev. 5: 605-616.

Pillus, L. and J. Rine. 1989. Epigenetic inheritance of transcriptional states in S. cerevisiae. Cell 59: 637-647.

Sherman, F., G. Fink, and J. Hicks. 1986. Methods in yeast genetics. Cold Spring Harbor Laboratory, Cold Spring Harbor, New York.

Shore, D., M. Squire, and K. Nasmyth. 1984. Characterization of two genes required for the position-effect control of yeast mating-type genes. EMBO I. 3: 2817-2823.

Shore, D., D. Stillman, A. Brand, and K. Nasmyth. 1987. Identification of silencer binding proteins from yeast: Possible roles in SIR control and DNA replication. EMBO J. 6: 461467.

Sikorski, R. and P. Hieter. 1989. A system of shuttle vectors and yeast host strains designed for efficient manipulation of DNA in Saccharomyces cerevisiae. Genetics 122: 19-27.

Singh, J. and A. Klar. 1992. Active genes in budding yeast display enhanced in vivo accessibility to foreign DNA methylases: A novel in vivo probe for chromatin structure of yeast. Genes \& Dev. 6: 186-196.

Sussel, L. and D. Shore. 1991. Separation of transcriptional activation and silencing functions of the RAP1-encoded repressor/activator protein 1: Isolation of viable mutants affecting both silencing and telomere length. Proc. Natl. Acad. Sci.
88: 7749-7753.

Wright, J., D. Gottschling, and V. Zakian. 1992. Saccharomyces telomeres assume a nonnucleosomal chromatin structure. Genes \& Dev. 6: 197-210. 


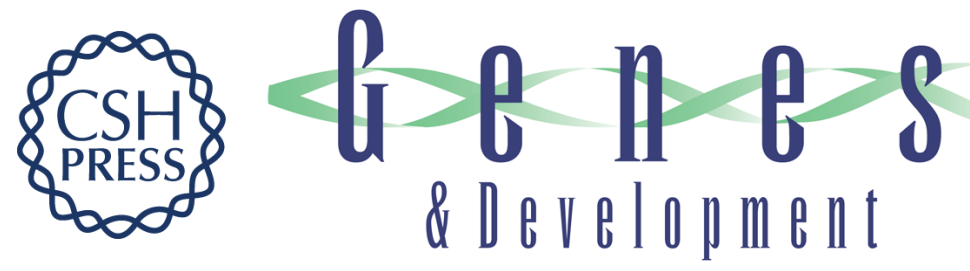

\section{RAP1 and telomere structure regulate telomere position effects in Saccharomyces cerevisiae.}

G Kyrion, K Liu, C Liu, et al.

Genes Dev. 1993, 7:

Access the most recent version at doi:10.1101/gad.7.7a.1146

References This article cites 31 articles, 17 of which can be accessed free at:

http://genesdev.cshlp.org/content/7/7a/1146.full.html\#ref-list-1

License

Email Alerting

Service

Receive free email alerts when new articles cite this article - sign up in the box at the top right corner of the article or click here.

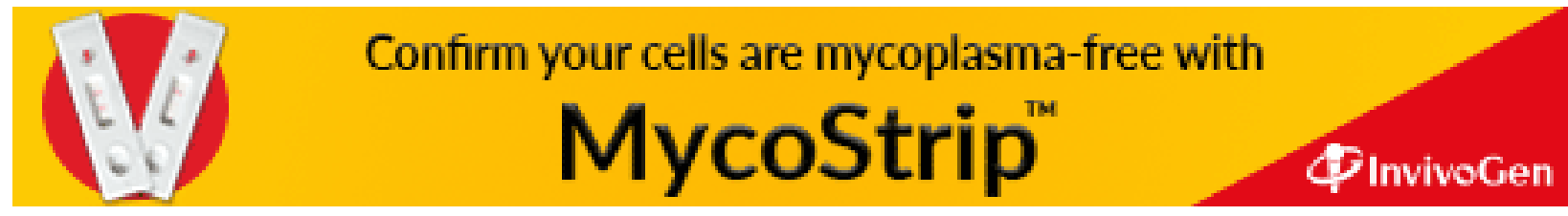

